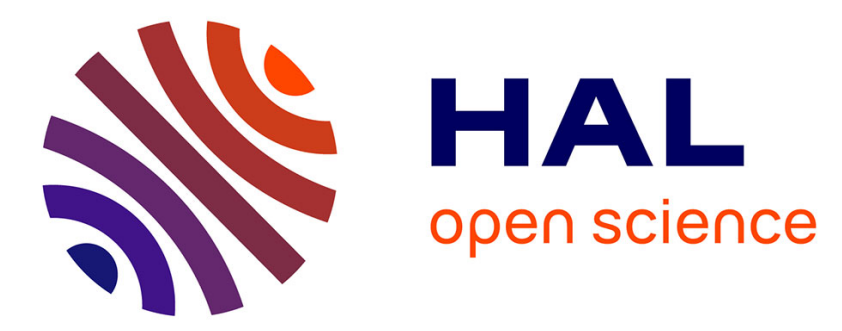

\title{
The 3-5 MHz global reflectivity map of Mars by MARSIS/Mars Express: implications for the current inventory of subsurface $\mathrm{HO}$
}

J. Mouginot, A. Pommerol, W. Kofman, P. Beck, B. Schmitt, A. Herique, C. Grima, A. Safaeinili, J.J. Plaut

\section{To cite this version:}

J. Mouginot, A. Pommerol, W. Kofman, P. Beck, B. Schmitt, et al.. The 3-5 MHz global reflectivity map of Mars by MARSIS/Mars Express: implications for the current inventory of subsurface HO. Icarus, 2010, 210 (2), pp.612. 10.1016/j.icarus.2010.07.003 . hal-00693814

\section{HAL Id: hal-00693814 https://hal.science/hal-00693814}

Submitted on 3 May 2012

HAL is a multi-disciplinary open access archive for the deposit and dissemination of scientific research documents, whether they are published or not. The documents may come from teaching and research institutions in France or abroad, or from public or private research centers.
L'archive ouverte pluridisciplinaire HAL, est destinée au dépôt et à la diffusion de documents scientifiques de niveau recherche, publiés ou non, émanant des établissements d'enseignement et de recherche français ou étrangers, des laboratoires publics ou privés. 


\section{Accepted Manuscript}

The 3-5 MHz global reflectivity map of Mars by MARSIS/Mars Express: implications for the current inventory of subsurface $\mathrm{H}_{2} \mathrm{O}$

J. Mouginot, A. Pommerol, W. Kofman, P. Beck, B. Schmitt, A. Herique, C. Grima, A. Safaeinili, J.J. Plaut

PII:

S0019-1035(10)00275-7

DOI:

10.1016/j.icarus.2010.07.003

Reference:

YICAR 9499

To appear in:

Icarus

Received Date:

5 February 2010

Revised Date:

28 June 2010

Accepted Date:

1 July 2010

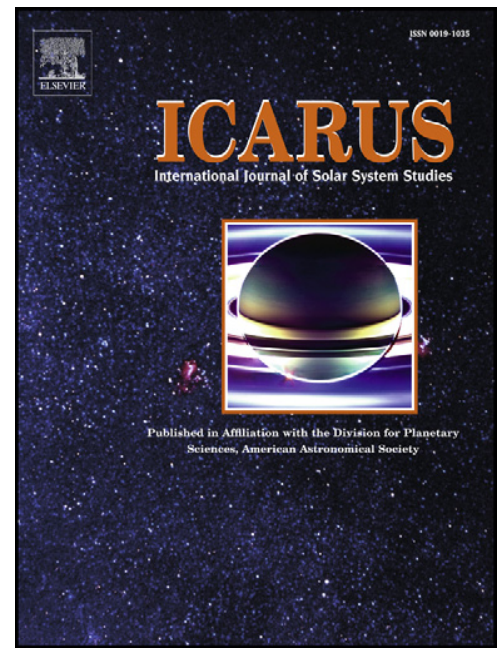

Please cite this article as: Mouginot, J., Pommerol, A., Kofman, W., Beck, P., Schmitt, B., Herique, A., Grima, C., Safaeinili, A., Plaut, J.J., The 3-5 MHz global reflectivity map of Mars by MARSIS/Mars Express: implications for the current inventory of subsurface $\mathrm{H}_{2} \mathrm{O}$, Icarus (2010), doi: 10.1016/j.icarus.2010.07.003

This is a PDF file of an unedited manuscript that has been accepted for publication. As a service to our customers we are providing this early version of the manuscript. The manuscript will undergo copyediting, typesetting, and review of the resulting proof before it is published in its final form. Please note that during the production process errors may be discovered which could affect the content, and all legal disclaimers that apply to the journal pertain. 
1 The 3-5 MHz global reflectivity map of Mars by

2 MARSIS/Mars Express: implications for the current

3 inventory of subsurface $\mathrm{H}_{2} \mathrm{O}$.

4

5 J. Mouginot ${ }^{1,2}$, A. Pommerol ${ }^{1,3}$, W. Kofman ${ }^{1}$, P. Beck $^{1}$, B. Schmitt ${ }^{1}$, A. Herique ${ }^{1}$, C.

6 Grima $^{1}$, A. Safaeinilii ${ }^{4}$ and J.J. Plaut ${ }^{4}$

7

$8 \quad{ }^{1}$ Laboratoire de Planétologie de Grenoble, UJF-Grenoble I/CNRS, France.

$9 \quad{ }^{2}$ University of California Irvine, CA, USA.

$10 \quad{ }^{3}$ Physikalisches Institut, Universitaet Bern, Switzerland.

$11{ }^{4}$ Jet Propulsion Laboratory, Pasadena, CA, USA.

12

13

14 To be submitted to Icarus

1540 pages

161 table

$17 \quad 10$ figures

18 


\section{Abstract}

20 measurements. The retrieved values are calibrated to compensate for changes in the distance of the spacecraft to the surface and for the attenuation of the signal by the ionosphere. The results are used to build the first global map of surface echo power at 3-5 MHz. The surface echo power variations are primarily caused by km-scale surface roughness. Then, we derive the values of dielectric constant of the shallow subsurface materials by normalizing the surface echo power map using a simulation of MARSIS signal from the MOLA topography. As a result, we obtain a map that characterizes the dielectric properties of the materials down to a few decameters below the surface. Dielectric properties vary with latitude, with high values in mid-latitudes belts (20$40^{\circ}$ ) and lower values at both equatorial and high latitudes. From the comparison of MARSIS reflectivity map to GRS observations, we conclude that the reflectivity decrease observed poleward of $50-60^{\circ}$ corresponds to the onset of water-ice occurrence within the regolith. Assuming homogenous ground composition and texture at the scale of the MARSIS resolution cell, our inferred volume of ground water ice is of $10^{6} \mathrm{~km}^{3}$, equivalent to a polar cap. Low reflectivity areas are also observed in equatorial regions. From radar studies alone, equatorial low dielectric constant values could have different interpretations but the correlation with GRS hydrogen distribution rather points toward a water related explanation. 


\section{1. Introduction}

The Martian surface has been scrutinized for decades by a variety of imaging and spectroscopic techniques, sensitive to the properties of the first micrometers to millimeters of the surface. Meanwhile, subsurface investigations remained limited to indirect studies until the arrival of the Mars Odyssey mission in 2001. Data from the Gamma Ray Spectrometer (GRS) were used to map the average chemical composition of the first meter below the surface (e.g. Boynton et al., 2007). The spatial distribution of hydrogen (inferred to be present in the form of ground ice) in both hemispheres is one of the major results of this instrument (Boyton et al., 2002; Feldman et al., 2002; Mitrofanov et al., 2002). In order to infer and map the properties of the Martian regolith and crust below this depth of $1 \mathrm{~m}$, "ground penetrating" geophysical techniques are required.

Whereas low frequency radar has been used in the past to probe the subsurface of Mars using terrestrial ground based instruments, the Mars Advanced Radar for Subsurface and Ionospheric Sounding instrument (MARSIS) on board Mars Express (Picardi et al. 2005) was the first radar sounder to operate from an orbiting probe around Mars. It has then been joined by the Shallow Subsurface Radar (SHARAD) on board Mars Reconnaissance Orbiter (Seu et al., 2007). MARSIS is a decameter radar sounder that operates in $1 \mathrm{MHz}$-wide frequency bands centered at 1.8, 3, 4 and 5 $\mathrm{MHz}$, whereas SHARAD operates at higher frequency $(20 \mathrm{MHz})$ and with a larger bandwidth (10 MHz), which leads to smaller penetration depth but higher vertical resolution. These two instruments measure 2D "radargrams" that represent crosssections of the Martian subsurface displaying discrete or continuous reflections of the radar waves at interfaces between materials of different dielectric constant (e.g. Plaut 
65

66

67

68

69

70

71

72

73

74

75

76

77

78

79

80

81

82

83

84

85

86

87

88

et al. 2007; Watters et al., 2007; Grima et al. 2009). Penetration depth of MARSIS can reach 4 kilometers in clear water ice (Plaut et al. 2007), and this instrument was able to map the bedrock/ice interface below Mars polar caps.

Here, instead of looking at individual radargrams, we build a global map of Mars by extracting the surface echo power from each frame (pulse) of each radargram. This so-called "reflectivity map" gives important information on the composition and physical properties of the upper part of the Martian crust at a global scale. Radar reflectivity maps of the Moon at different frequencies have already been measured in the past from ground-based instruments and used to infer important properties of the Lunar terrains (Evans 1962; Evans and Pettengill 1963). In particular, Campbell and Hawke, 2005 show that reflectivity values measured at the wavelength: $\lambda=70 \mathrm{~cm}$ can be influenced by the composition of terrains buried more than $50 \mathrm{~m}$ deep in some cases, demonstrating the ability of this method to probe at large depth. In the case of Mars, some measurements had also been obtained using ground based radio telescopes at $\lambda=3.5$ to $70 \mathrm{~cm}$ (Simpson et al., 1992; Harmon et al., 1999) or spacecraft as Mars-3 and Mars-4 spacecraft (Krupenio et al. 1977) and Viking orbiter 2 at $\lambda=13.1 \mathrm{~cm}$ (Simpson et al., 1979) but were rather limited in terms of spatial resolution and / or geographic extent. The reflectivity values obtained from these measurements have been used to estimate the dielectric constant of surface materials (Pettengill et al., 1973; Downs et al., 1973, 1975; Simpson et al., 1982). Spatial variability of the value of the dielectric constant has been interpreted in terms of variations of bulk density (Krupenio et al. 1977) and/or compositional variations (Campbell and Ulrich, 1969) of subsurface materials.

In this article, we present the method used to extract the surface echo power, 
89 and the corrections required to build the global dielectric map from MARSIS

90 measurements. We show that the obtained map provides unique information on the

91 nature of the surface geological material, and more generally on Mars geology and

92 climatology.

93 


\section{2. Methods}

95

96

97

98

99

100

101

102

103

104

105

106

107

108

$$
C(i)=\frac{|S(i)|^{2}}{\operatorname{mean}\left(|S(i-1: i-30)|^{2}\right)}
$$

where $S$ is the MARSIS signal in a given frame (512 samples) and $i$ is the temporal

111 index inside the frame. Equation 1 computes the contrast between a bin and the signal

112 average over the 30-bin window preceding it.

$$
C \text { is maximum when }|S(i)|^{2} \text { is maximum and mean }\left(|S(i-1: i-30)|^{2}\right) \text {, equal to }
$$

114 the power level of the noise galactic and thermal), is minimum. This condition is only 115 satisfied for the surface echo, i.e. the only echo that can precede the surface echo is a 116 noise. An example of detection is given in figure 2 for orbit 2787. Once the surface 
117 signal has been identified, the amplitude of the surface echo can easily be extracted as

118 shown on figure 1.

We have systematically applied this process to the MARSIS data, between orbit 2300 and orbit 5200. Respectively about $0.6,1.3$ and 0.8 millions of measurements were extracted from the frequency bands centered at 3, 4 and $5 \mathrm{MHz}$.

Band 1, centered at $1.8 \mathrm{MHz}$, is not used in this study because the number of measurements was too small.

\subsection{Estimation of surface echo power}

The surface echo power largely depends on the attenuation of the

128 electromagnetic waves between the spacecraft and the surface, which is mainly due to 129 range attenuation and ionospheric absorption. In the following sections, we describe 130 the method used to correct these effects.

\section{$132 \quad$ 2.2.1. Range attenuation}

135 equation applying Snell's law for a vertically incident electromagnetic wave on a flat 136 surface. When we assume altitude of the satellite as $\mathrm{R}$, the peak power of surface echo 137 can be estimated as: 
140 gain, the wavelength and the reflectivity of the surface, respectively. Thus, the

141 intensity of a surface echo is mainly dependent on the propagation range $R$, the

142 observation wavelength $\lambda=2 \pi c / \omega$ and antenna gain $G(G=1.64$ for a matched dipole 143 antenna condition).

144 The received power decreases with $R^{2}$ (equation 2). The Mars Express orbit is 145 elliptical and the spacecraft altitude during MARSIS passes varies between about 250 146 and $1000 \mathrm{~km}$. It is therefore necessary to compensate for the power losses due to 147 altitude change, and we simply normalize the surface echo power by the squared 148 altitude of the spacecraft.

\subsubsection{Ionospheric absorption}

151

152

As described by Safaeinili et al. (2003), the plasma layer (ionosphere)

attenuates the MARSIS radar waves. The attenuation of electromagnetic waves per meter of ionospheric plasma is given by:

$$
A=4.61 \times 10^{-5} \frac{n_{e}(z) v(z)}{\omega^{2}+v(z)^{2}}
$$

156 where $n_{e}$ is the electron density $\left(\mathrm{m}^{-3}\right)$ at altitude $z(\mathrm{~m}), v$ the electron collision

157 frequency $\left(\operatorname{rad~s}^{-1}\right)$ and $\omega$ is the pulsation of the radar wave (radian frequency).

For MARSIS data, we have a two-way ionospheric propagation and the total

159 attenuation of the radar waves therefore becomes:

160

$$
\int A d z=2 \times 4.61 \times 10^{-5} \int \frac{n_{e}(z) v(z)}{\omega^{2}+v(z)^{2}} d z
$$


162

163

164

165

166

167

168

169

170

171

172

173

174

175

176

177

178

179

180

182

183

184

185

density and collision frequency profiles that depend on the neutral density. As these profiles are related to the ionization due to the solar EUV (extreme ultra violet) radiation, the absorption changes on Mars have a first order dependence on solar zenith angle. Safaeinili et al. (2003) have described in detail this phenomenon for different states (day/night, etc...) of the Martian ionosphere.

An accurate estimation of absorption requires knowledge of the exact state of the ionosphere and the neutral atmosphere (i.e. the density and collision profiles) for each frame. These profiles are not measured and therefore we cannot precisely calculate absorption. However, the correction of the dispersion effect (variation of wave velocity with frequency) due to the ionosphere (Safaeinili et al. 2007, Mouginot et al. 2008) provides a value of the total electron content (TEC) and, as TEC is the integral of the electron density, this value is a good proxy to estimate absorption.

Figure 3a shows that the surface echo power on MARSIS data decreases as TEC increases. In this figure, we used the entire set of signal measurements for the 4 $\mathrm{MHz}$ band. For a given value of TEC, the surface echo power varies over a $10 \mathrm{~dB}$ range due to the variable reflectivity of the different Martian terrains. This trend is consistent with equation 4, which shows that electron density enhances absorption.

The signal decreases until a threshold is reached at about $30 \mathrm{~dB}$ below the maximum power. This threshold corresponds to the MARSIS noise level. Table 1 summarizes, for each frequency band, the values of SZA (Solar Zenith Angle) or TEC at which the signal becomes lost in the noise. We have chosen to remove the data outside the limits defined in Table 1. Furthermore, we did not use observations that show a very low signal power. In these cases, very high attenuation is probably due to the increased electron density created by precipitation and radiation during solar flares 
186 206 Mouginot et al. 2008).

(Espley et al. 2007).

The next step consists in evaluating the behavior of the surface echo power as a function of the TEC values. We compute the mean surface echo power for the overall data set with a bin for TEC of $2 \times 10^{13}$ electrons per square meter. The result is presented in figure $3 \mathrm{~b}$. We use this curve of mean surface echo power as function of TEC to normalize the data to compensate for absorption. The normalized data plotted in figure 4 are constant on average as function of TEC.

\subsection{Surface echo power}

After extracting the surface echo power from the echo histories and correcting them for range dependence and ionospheric absorption, we plot the global map of the surface echo power in figure 5a. We averaged the data from multiple measurements with a bin size of 0.5 degrees. MARSIS is a nadir-looking radar and the Mars Express polar orbit does not allow us to sound the surface beyond about $87^{\circ} \mathrm{N}$ and $87^{\circ} \mathrm{S}$. The surface echo power values for the different frequency bands are very similar and have thus been combined on this map to provide better coverage of the Martian surface. However for local or regional studies, it could also be useful in the future to compare the reflectivity measured in several frequency bands to study materials and/or structures that could change the surface reflectivity as a function of frequency (e.g.,

Several parameters might affect the surface echo power: surface roughness, slope distribution and the dielectric constant of the surface materials. Most backscattering models separate the effect of the dielectric constant (material 
210

211

212 equation:

$213 r_{0,1}=\Gamma_{s}(\varepsilon) f_{s}\left(r m s_{s}, \lambda\right)(5)$

214 where $\Gamma_{s}$ is the Fresnel reflectivity terms and $f_{s}$ is the backscattering term (geometric

215 scattering). The function $f_{s}$ is only dependent on the surface topography (i.e. the

216 roughness and the slopes).

217 The surface roughness at MARSIS wavelength is due to slight variations of 218 the surface heights over horizontal scale of the tens to hundred meters (figure $5 \mathrm{c}$ ). The 219 slope distribution effect is due to surface altitude variation on a scale of a few hundred 220 to thousands meters. The surface echo is made from nadir return, which is a coherent 221 specular reflection of the emitted wave at the surface interface. This nadir echo is 222 mainly reflected on the first Fresnel zone, which has a diameter varying between 5 223 and $16 \mathrm{~km}$ (depending on the spacecraft altitude and emitted wavelength). The slope 224 distribution inside the first Fresnel zone results in a scattering of the signal to off225 nadir directions, which is related to a decrease of surface reflectivity.

226 As expected for a decametric radar waves, we observe in figure 5 that the 227 roughness at kilometer-scale (Kreslavsky and Head, 2000) is highly correlated to the 228 surface reflectivity due to slope distribution effect. The roughest terrains on Mars, 229 such as the Olympus Mons aureole, Valles Marineris, the Argyre crater rim display 230 very low surface echo power. Highlands Plateau, which is a heavily cratered region in 231 the southern hemisphere, presents globally a lower reflectivity compared to the 232 smoother northern plains (Vastistas Borealis). The smoothest terrains as the volcanic 233 plateau in Tharsis region or Amazonis Planitia are characterized by a very high 234 reflectivity. 
Only few localized terrains that are smooth at kilometer-scale present low

236 reflectivity, such as the linear dune regions around the north polar cap (mostly in

237 Olympia Planitia), which are very rough at small scales and smoother at large scales

238 (Kreslavsky and Head, 2000). An image (figure 6) provided by the High Resolution

239 Imaging Science Experiment (HiRISE) on board Mars Reconnaissance Orbiter

240 (MRO) illustrates this small-scale roughness, showing dunes spaced in the range of

241 50-100 m, which corresponds exactly to the range of MARSIS wavelength. In this

242 particular case, the coherent part of the signal vanishes and only the incoherent part

243 (clutter) remains, as observed on the radargrams of orbit \#3674 between frames 80

244 and 130 (figure 6). This region is typically an area where the roughness effect on the

245 signal is really strong compared to the effect of slope distribution.

246 However, only few regions are really rough at 10-100 meters scale and it

247 seems that the main effect on surface reflectivity is due to slope distribution

248 (kilometer-scale roughness). In addition, due to the lack of a global DEM at the

249 required spatial resolution, we cannot model the effect of small scale $(<100 \mathrm{~m})$

250 roughness. Thus, we have decided to neglect the effect of this roughness and to only

251 take into account the larger-scale slope distribution. Locally, this assumption could be

252 wrong (i.e. dune fields shown in figure 6). In such a case, we expect errors on the

253 retrieved reflectivity values up to $3 \mathrm{~dB}$ (Campbell and Shepard, 2003). However,

254 comparisons of the final dielectric map (figures 7 and 8) with the MOLA pulse width

255 map (Neumann et al., 2003), which describes roughness at 1-20 m and SHARAD

256 reflectivity map (unpublished data) which is sensitive to $1-15 \mathrm{~m}$ roughness do not

257 show any systematic correlation at global scale. Therefore, we do not think that

258 neglecting the $<100$ roughness has any major effect for this global scale study. 


\subsection{Simulation of MARSIS data}

261

262

263

264

265

266

267

268

269

270

271

272

273

274

275

276

277

278

279

280

281

282

283

284

In order to obtain maps showing the dielectric properties of surface materials, we have to correct for the effects of relief on the signal and then calibrate the resulting reflectivity. A method for simulating MARSIS echo histories due to local topography has been developed to help in the interpretation of the observational data. For this simulation, the surface is modeled using the facet method (Nouvel 2002; Nouvel et al. 2004), which is an extension of the Kirchhoff model. Such a model can be used because of the low surface roughness at radar wavelengths and offers a significant gain in calculation time. The synthetic faceted surface is generated from MOLA data (Smith et al. 2001).

All MARSIS orbits have been simulated and we have extracted the surface echo power in the same way as for actual MARSIS data. The dielectric constant of the surface is kept constant in the simulation. Thus, the simulation makes possible the estimation of the contribution of large-scale scattering resulting from slope distribution. We can now consider the simulation as a reference for the surface echo power in order to correct the roughness and topographic effects.

The result of all the simulations is shown in figure $5 \mathrm{~b}$ as a global map of the expected surface echo power of the Martian surface. Note that the Olympia Planitia region is characterized by a high-simulated surface echo power compared to the real power (see figure 5a). As the facet size in the simulation is about $460 \mathrm{~m}$ (due to the limited MOLA resolution), the topography of the dunes is not captured by the digital elevation model. This shows the limit of the simulation that is unable to simulate the small-scale scattering resulting from surface roughness over a horizontal scale of tens of meters or less. 
286 echo power extracted from the MARSIS data. Finally we estimate the Fresnel 287 reflectivity $\Gamma_{s}(\varepsilon)$ by dividing the MARSIS data by the simulated data (see equation 5).

288 The result of this correction is shown in figure 7.

289 The Fresnel reflection coefficient $\Gamma_{s}(\varepsilon)$ at normal incidence at the plane interface 290 between two media with refractive indexes $n_{i}$ and $n_{j}$ respectively is defined as 291 followed:

$292 \Gamma=\frac{n_{i}-n_{j}}{n_{i}+n_{j}}(6)$

293 The relation between the dielectric constant $\varepsilon$ and refractive index $n$ is $n=\sqrt{\varepsilon}$. The

294 reflectivity of an interface is given by $R=|\Gamma|^{2}$. For the surface interface, the equation 2956 can be reduced to:

$296 \Gamma=\frac{1-n_{j}}{1+n_{j}}(7)$

297 where $n_{j}$ is the refractive index of the surface materials and $n_{i}$, the refractive index of 298 the atmosphere taken as 1.

299 Using equation 7, we easily convert $\Gamma_{s}(\varepsilon)$ into dielectric constant.

300 As the received power is still not calibrated in an absolute way, we use the regions of 301 the North and South Polar Layered Deposits (NPLD and SPLD) as a reference. We 302 adjusted the result in figure 7 by multiplying the whole map by a constant. This 303 constant is evaluated such that the estimated water ice reflectivity values in polar 304 layered deposit is matched (Plaut et al. 2007, Grima et al. 2009). We use: $\varepsilon^{\prime}=3.1$ and $305 \Gamma=0.275$. We can test the validity of this method by comparing our estimates of 306 dielectric constant to the values determined in the Ascraeus Mons region by Carter et 307 al. (2009). By analyzing SHARAD radar signal propagation between the surface and 
308 shallow interfaces, they found values of permittivity ranging from 6.2 to 17.3 in the

309 Northern volcanic flows, with an average of 12.2, while in the southern volcanic flow, 310 values between 7.0 and 14.0 were estimated with an average of 9.8. In the same area,

311 the value we estimate for this area using surface power echo is of $11_{-4}^{+11}(n=80)$. This

312 result is in fair agreement with Carter et al. (2009).

313 


\section{Results and discussion}

\subsection{Global geographic variations} variations over the planet. The most obvious feature is the latitude-dependent pattern in reflectivity. The equatorial region displays generally low values, the mid-latitudes generally high values, and the high latitudes generally low values again. The lowreflectivity pattern in the equatorial regions is interrupted by very high reflectivity on the Tharsis volcanic plateau, including Solis, Sinai and Daedalia plana, and the area between the Tharsis Montes and Olympus Mons. In the mid-latitude bands, the largest continuous patch of high reflectivity is on the northern side of the Elysium Mons shield. The northern high latitudes are generally lower in reflectivity than the southern high latitudes, with the exception of the area north of Alba Patera. The south residual polar cap has a very low reflectivity due to interferences within the thin layer of $\mathrm{CO}_{2}$ ice, causing much weaker surface reflections compared to reflections from a pure water ice surface as described in details by Mouginot et al. 2009. Bands of apparent

331 low reflectivity in the Terra Cimmeria region are probably uncorrected artifacts

332 related to the interaction of the remnant crustal magnetics and the ionosphere 333 (Safaeinili et al. 2007, Mouginot et al. 2008).

Two main parameters are likely to control the dielectric constant of the layer involved in the reflection process: the composition (chemistry, mineralogy, water

336 content and physical state) and the density of the constituent materials. Because water 337 ice presents a low dielectric constant (typically $\sim 3.1)$ compared to igneous rocks $(\sim 8)$ 
339 involved in the reflection process will lead to a decrease in surface reflectivity,

340 compared to a dry, dense rock layer. However, low-density materials can also lead to

341 such low values of the effective dielectric constant and the use of complementary

342 datasets is crucial to build robust interpretations. We undertook systematic

343 comparisons between the MARSIS surface dielectric map, visible albedo maps,

344 topographic maps, the water concentration map derived from neutron spectroscopy,

345 and the thermal inertia map derived from TES (Thermal Emission Spectrometer on

346 Mars Global Surveyor) data.

\subsection{Latitudinal variations and the onset of ground-ice}

Examination of the MARSIS global map (figure 8a, b) and the corresponding

351 longitudinally averaged profile (figure 9) reveals a strong latitudinal dependence of 352 dielectric constant. For both hemispheres, the highest values (6 - 10) are observed at 353 tropical latitudes. These values are in agreement with laboratory measurements on dry 354 igneous rocks (Campbell and Ulrichs, 1969; Heggy et al., 2007) and are consistent 355 with igneous basaltic to granitic rocks. Variations of materials density are probably 356 responsible for the observed variability of the dielectric constant within igneous 357 terrains.

Poleward of around $50-60^{\circ}$ in both hemispheres, terrains show a steep

359 decrease of dielectric constant down to values of 3-4. Climate related processes are

360 likely responsible for the observed latitudinal variations (Head et al., 2003), and the

361 comparison with other observations of the Martian surface strongly suggests that this

362 dielectric constant decrease corresponds to the onset of water-ice occurrence within

363 the regolith. For the current average water vapor atmospheric content, the frost point 
364 at Mars surface is around $200 \mathrm{~K}$. Average temperatures below the frost point are

365 reached for latitudes in excess of 30 to $45^{\circ}$ in the Northern hemisphere and $40^{\circ}$ in the

366 Southern hemisphere. Permanent stability of water ice is possible at depth, where the

367 sub-surface is insulated from the diurnal and seasonal temperature fluctuations. As

368 ice is not stable on the surface, we expect the ground ice to be overlaid by a layer of

369 dry regolith whose thickness depends on latitude, soil physical properties, and the

370 seasonal evolution of surface humidity (Mellon and Jakosky, 1991; Schorghofer and

371 Aharonson, 2005).

The MARSIS dielectric transition is not associated to a systematic change in

373 surface albedo or thermal inertia (figure 10), which implies that the surface

374 geological material does not change much upon crossing this transition. There is a

375 general agreement between the latitudinal distribution of near-surface ( top meter)

376 ground ice detected by GRS and the dielectric decrease observed by MARSIS

377 (figures 8 and 10). In the case of the southern hemisphere there is a good agreement

378 between the latitude of the ground-ice determined by MARSIS and GRS, with an

379 average latitude of $48-50^{\circ}$, almost constant with regard to longitude. This ground-ice

380 extent is also in good agreement with the calculated stability limit for the currently

381 observed atmospheric conditions (Mellon and Jakosky, 1991; Schorghofer and

382 Aharonson, 2005). This suggests that the icy layer is in equilibrium with the current

383 climatology.

In the case of the Northern hemisphere, the transition between low and high reflectivity terrains is generally shifted equatorward compared to the ground-ice limit detected by GRS and shows some longitudinal variations (figure 8). Most of this longitudinal variability is likely related to spatial variations of the terrains' physical properties and not to distribution of water ice. Particularly high dielectric values 
389

390

391

392

393

394

395

396

397

398

400

401

402

403

404

405

406

407

408

409

observed at high latitudes in the north Tharsis region are likely caused by a higher density of the near-surface materials. Excluding these regions, the MARSIS groundice limit appears shifted equatorward by $6-7^{\circ}$ compared to the GRS ground-ice limit. Recent evidences for the presence of ground ice at latitude as low as $43^{\circ} \mathrm{N}$ have been reported in Arcadia Planitia. Young craters were found to have excavated bright materials with the diagnostic spectral features of water-ice (Byrne et al., 2009). The location of these craters is consistent with the MARSIS limit of ground-ice occurrence. The bright ice deposits excavated by these young craters as well as the ground ice sampled by the Phoenix Lander both point to the presence of layers of nearly pure ice below the regolith.

Preliminary MARSIS estimates of ice fraction for the Northern latitudes (50 $100 \%$ by volume, see section 3.3) would also imply the presence of water ice in excess of the regolith porosity. In the Southern hemisphere, estimated values do not allow us to firmly constrain the origin of ground ice. Such a mode of occurrence is inconsistent with pore-filling ice emplaced by direct condensation from atmospheric water vapor. It requires the deposition of an ice-rich material on the surface, such as frost or snow, then buried under a layer of dry regolith formed either by sublimation of dusty ice or by wind transport. Morphologic evidences support this interpretation for both Northern and Southern ground-ice (Head et al., 2003). Repeated freeze thaw (due to long-term variations in obliquity) of an initially ice-saturated regolith can also result in the migration of thin films of adsorbed water along mineral grain surfaces in response to the presence of a temperature gradient. On Earth, this process can result in the formation of massive ice deposits/lenses (Washburn 1980; Williams and Smith 1989), which could also explain the Phoenix and GRS observations. However, this mechanism is unlikely to explain ice concentrations of $50-100 \%$ to depth $>60 \mathrm{~m}$ into 
414 the subsurface. Beyond the in situ enrichment of ice by repeated freeze/thaw (or the

415 deposition of massive mantles of ice) in response to obliquity variations, there is also

416 the potential survival of water discharged by the outflow channels (Carr 1990) - or

417 the survival of frozen relic of an early ocean (Clifford and Parker, 2001).

\subsection{Estimation of the volume of water-ice seen by MARSIS}

water-ice content of the ground based on reflectivity values measured by MARSIS in

a simple and ideal case. The accurate inversion of reflectivity values in terms of ground ice content is indeed a challenging task that requires a complete physical modeling of the radar waves reflection process and the knowledge of various properties of the ground. If some of these properties remain unconstrained (layering, density...), it is likely that different models of subsurface composition and structure can lead to similar values of reflectivity, i.e. the inversion process does not lead to a unique solution. Our future work on the retrieval of subsurface composition and 430 texture from MARSIS absolute reflectivity values, based on physical modeling, will 431 be focused on these issues but is beyond the scope of this first study. Here, we calculate the order of magnitude of the amount of water ice required in the subsurface to account for the values of reflectivity measured by MARSIS assuming a

434 homogeneous composition at the scale of a MARSIS resolution cell and fixed 435 parameters for the texture of the ground. By doing that, we aim to provide to the 436 reader an idea of the quantity of ice that can be probed by our method and set a 437 starting point for future studies that will refine the rough value estimated here. In the framework of the simple investigated hypothesis, two values have to be estimated to 
439 calculate the quantity of water ice: the thickness of the layer probed by the reflection

440 of the electromagnetic waves on the surface and the ice/rock ratio in this 441 homogeneous layer.

442

$443 \quad$ 3.3.1 Thickness of the probed layer

444

The reflectivity coefficient we determine is related to the permittivity of the

446 surface materials. If one supposes that the subsurface is an infinite homogenous half-

447 space, MARSIS is directly probing the specular reflection of the radar wave. The 448 depth involved in the reflection process is thus given by the skin effect. The loss is 449 given by:

$450 \quad \alpha=0.091 f \sqrt{\varepsilon} \tan (\delta)$

451 Where $f$ is the frequency (in MHz) and $\tan (\delta$ ) the loss tangent.

452 From the value of $\alpha$ one might calculate the skin depth by using:

$$
d=\frac{10 \log _{10} e}{\alpha}
$$

454 Loss tangent for Mars surface rocky materials are expected to vary between 0.004 and 4550.03 (Picardi et al., 2004) at $5 \mathrm{MHz}$ and were measured to be within the 0.01-0.03 456 range (at $20 \mathrm{MHz}$ ) for lava flows west of Ascraeus Mons (Carter et al., 2009). Using $457 \quad 0.004$ and 0.03 as likely extreme values for the loss tangent, we find the 458 corresponding values for the skin depth to be 780 and $100 \mathrm{~m}$ respectively.

459 The MARSIS radar signal has a temporal resolution of $\Delta t=1 \mu$ s that is equivalent to 460 a propagation length in the media of $2 L=c \Delta t / \sqrt{\tilde{\varepsilon}}$ Because this distance is smaller 
461

462

463

464

465

466

467

468

469

470

471

472

473

474

475

476

477

$$
\varepsilon_{e f f}=\varepsilon_{e}+3 f \varepsilon_{e} \frac{\varepsilon_{i}-\varepsilon_{e}}{\varepsilon_{i}+2 \varepsilon_{e}-f\left(\varepsilon_{i}-\varepsilon_{e}\right)}
$$

478 The inversion of dielectric constant value measured by MARSIS in terms of 479 ice / rock ratio requires the knowledge of the dielectric constants of the pure end480 members. If the value of $\varepsilon^{\prime}=3.1$ for pure water ice at MARSIS wavelength is 481 commonly accepted (Petrenko, 1999) and is not likely to be subject to strong spatial 482 or temporal variations, the choice of a value for the rocky component of the mixture is 483 more problematic. Usually the dielectric constants for volcanic rocky materials are 
484

485

486

487

488

489

490

491

492

493

494

495

496

497

498

499

500

501

502

503

504

comprised between 6 and 11 (Campbell and Ulrichs, 1969). The mean value found in tropical regions by MARSIS is 6.5. Thus, we assume that the dielectric constant of the dry rock chosen for our calculations are the same as the one measured by MARSIS in equatorial regions. The chosen value is relatively low and even if the nature of the soil changes in certain regions, we can give a lower estimate of the ice / rock mixing ratio. We obtain values of the ice / rock volume mixing ratio of the order of $50 \%$ in the Southern and between 50 and $100 \%$ in the Northern. Although the variability is high, it appears that the average amount of ice present in the subsurface is higher in the Northern hemisphere that in the Southern hemisphere. Furthermore, other observations point to systematic differences between the two hemispheres (see section $3.3)$.

The total amount of water stored in the two Martian polar layered terrains (Plaut et al., 2007, Smith et al., 2001) is estimated to be $2.810^{6} \mathrm{~km}^{3}$. The atmosphere contains the equivalent of $\sim 3 \mathrm{~km}^{3}$ of condensed water (Plaut et al., 2001). The total amount of water contained in the subsurface is certainly the main uncertainty in the current inventory of water on Mars. While neutron spectroscopy permitted an estimation of the amount and extent of ice in the top meter of the regolith, low frequency radar techniques now offer the unique opportunity to probe the regolith and quantify the amount of ice at decameters to kilometers scale. In the framework of the ideal hypothesis of a homogeneous subsurface considered in this paragraph, we can estimate the total amount of ground water ice necessary to explain the low values of reflectivity measured by MARSIS. Considering the measured extent of both Northern and Southern ground-ice, the average ice / rock ratio obtained from inversion of MARSIS dielectric measurements and a probed thickness of 60-80 meters, we estimate the potential lower limit of the total volume of ice currently stored at high 
509 latitude in the ground to be $\sim 10^{6} \mathrm{~km}^{3}$, of the order of magnitude of the volume of one

510 of the polar caps. As already mentioned at the beginning of this paragraph, future

511 studies dedicated to the physical modeling of the radar reflection process should now

512 be undertaken to examine the influence of the heterogeneity of the subsurface on the

513 inversion of dielectric values in terms of amount of water ice in the subsurface. The

514 case of meters-thick lenses of pure water ice close to the surface should be

515 investigated in priority as this ground structure has been mentioned to interpret recent

516 datasets, especially in-situ observations by the Phoenix Lander (Smith et al., 2009). 


\section{$518 \quad 3.4$ Tropical and equatorial minima}

519

520

521

522

523

524

525

526

527

528

529

530

531

532

533

534 the regolith is still debated. Different explanations have been proposed, like a high 535 abundance of nominally hydrated minerals (Fialips et al., 2005), an interaction of the 536 regolith with atmospheric water vapor (Feldman et al., 2005), or the presence of 537 transient ground ice (Jakosky et al., 2005).

Examination of the MARSIS surface dielectric map in the equatorial to tropical regions reveals the occurrence of a nearly continuous low reflectivity belt between $-30^{\circ}$ and $+30^{\circ}$ latitude. Extremely low values are reached in the Medussae Fossae area $(\varepsilon \approx 3)$ (figure 8 and 10). Other minima are encountered in the areas of Meridiani Planum $(\varepsilon \approx 4)$ and from Isidis basin to the highlands south of Elysium Planitia $(\varepsilon=3.5)$. The low values of dielectric constants can have various origins: different composition of rocks, low density of surface material, presence of water ice buried beneath a desiccated regolith... Radar measurements alone do not allow discriminating between these different possibilities. When compared to other datasets, it appears that, as in the polar regions, the best match for the MARSIS reflectivity equatorial pattern is obtained from comparison with the GRS WEH map. Indeed, the low reflectivity regions roughly correspond to regions that were shown to be enriched in hydrogen by the GRS instrument suite, with WEH values up to $12 \%$. The interpretation of high hydrogen enrichments detected by GRS in the top first meter of

The spatial agreement between the low-reflectivity values on the MARSIS map and the H-enriched areas on the GRS map strongly points toward a water-related explanation. In particular, the Medusae Fossae formation terrains, when sounded by MARSIS (Watters et al., 2007), were found to have a bulk real dielectric constant $\varepsilon=2.9 \pm 0.4$, in agreement with our near-surface estimate. The authors proposed two 
543 hypotheses to explain these low values: low-density volcanic deposits or the presence

544 of ice, deposited during a high-obliquity/high-humidity climatic excursion that is 545 currently sublimating at some depth and hydrating the overlying regolith. Spatial 546 correlation between MARSIS and GRS measurements supports this last hypothesis.

547 Unfortunately, the new MARSIS results do not generally allow arguing in favor or

548 one or another of the hypotheses proposed to explain high WEH values measured by

549 GRS. Indeed, the presence of low density / highly hydrated sedimentary materials, 550 such as the ones observed in-situ by the Opportunity rover in Meridiani Planum 551 (Squyres et al., 2004) could explain the observed low radar reflectivity because of 552 their low dielectric constant (Campbell and Ulrichs, 1969) as well as the presence of 553 ground ice as already discussed for high latitudes regions.

554 If the MARSIS radar map does not allow us to choose unambiguously 555 between the pre-cited mechanisms, its main implication is that anomalous surface 556 hydrogen enrichments detected by GRS correspond to anomalies of dielectric 557 constant, possibly related to the presence of $\mathrm{H}_{2} \mathrm{O}$ in an unconstrained state, extending 558 down to at least a few decameters below the surface. This is a new and important 559 constraint on the nature and origin of the equatorial anomalies that should be taken 560 into account in future interpretations of these regions. 


\section{Conclusion}

565

A global 3-5 MHz dielectric map of the Martian surface is built from two

567 years of measurements by the MARSIS instrument. Using MOLA topographic data,

568 we corrected the effect of kilometer-scale roughness and slopes to retrieve the spatial

569 variations of the dielectric constant of near-surface materials. Many parameters are

570 susceptible to influence the dielectric constant of the top decameters below the surface

571 that are probed by the radar wave reflection process. With the use of complementary

572 datasets, we were able to interpret the geographic variations of radar reflectivity in

573 term of surface geological material. From the comparison of the MARSIS map with

574 the hydrogen abundance map derived from GRS measurements, we show that low

575 dielectric values at latitudes poleward of 50-60 are likely to be due to high amount of

576 water ice in the ground.

577 The thickness probed by the MARSIS surface reflectivity is of the order of a 578 few decameters, resulting in a significant increase of the total quantity of ground ice 579 compared to GRS observations, only representative of the first meter below the 580 surface. Assuming a homogenous composition of the ground at the scale of a 581 MARSIS resolution cell as a simple first-order hypothesis, measured values of 582 dielectric constant lead to a minimum estimate of ice stored in the Martian sub583 surface to be of the order $\sim 10^{6} \mathrm{~km}^{3}$, equivalent to a polar cap. Future studies focused 584 on the physical modeling of the reflection process over more realistic models of the 585 subsurface structure and texture will be necessary to refine this rough estimation.

586 At least in the Northern hemisphere the amount of ice appears to be in excess 587 of porosity. Refined analysis of the frequency dependence of the surface reflectivity, 588 together with laboratory measurements of the dispersion relation of ice-rock mixture 
589 might help in confirming this observation that would have strong implication for the

590 mechanism of ground ice emplacement.

591 Puzzling anomalies in hydrogen at equatorial latitudes first revealed by the

592 GRS instrument correspond to low reflectivity areas on the MARSIS map. If low

593 reflectivity alone does not permit to discuss further the origin of the hydrogen

594 anomalies, presence of highly hydrated minerals or shallow buried ice, it tells us that

595 the anomalies identified by GRS in the near subsurface actually extend in depth to the

596 first decameters below the surface. 


\section{Acknowledgments}

598

This article is dedicated to the memory of Ali Safaeinili (1964-2009) and his

600 immeasurable contribution to radar sounder development and scientific exploitation.

601 The authors would like to thank the reviewers (Clifford S.M. and Campbell

602 B.A.) for their comments that help improve the manuscript.

603 We acknowledge the support of the space agencies of Italy (ASI) and the

604 United States (NASA), for the development and science operations of MARSIS.

605 Operations of the Mars Express spacecraft by the European Space Agency (ESA) are

606 gratefully acknowledged. The French space agency (CNES) supports these studies in

607 Laboratoire de Planétologie de Grenoble.

608 


\section{References}

610 Aharonson, O., Zuber, M. T. and Rothman, D. H., 2001. Statistics of Mars'

611 topography from the Mars Orbiter Laser Altimeter: Slopes, correlations, and physical

612 models, J. Geophys. Res., 106, 23723-23736, doi: 10.1029/2000JE001403

613 Boynton, W. V, and 24 colleagues, 2002. Distribution of Hydrogen in the Near

614 Surface of Mars: Evidence for Subsurface Ice Deposits, Science, 297, 81-85

615 Boynton, W. V., and 27 colleagues, 2007. Concentration of H, Si, Cl, K, Fe, and Th in 616 the low- and mid-latitude regions of Mars. Journal of Geophysical Research-Planets. $617112,15$.

618 Byrne, S., and 17 colleagues, 2009. Distribution of Mid-latitude Ground Ice on Mars 619 from New Impact Craters, Science, 325, 1674-1680.

620 Campbell, M. J., Ulrichs, J., 1969. Electrical properties of rocks and their significance 621 for lunar radar observations, J. Geophys. Res., 74, 5867-5881.

622 Campbell, B. A., Shepard, M. K., 2003. Coherent and incoherent components in near623 nadir radar scattering: Applications to radar sounding of Mars, J. Geophys. Res., 624 Volume 108, Issue E12, pp. 6-1.

625 Campbell, B. A., Hawke, B R., 2005. Radar mapping of lunar cryptomaria east of 626 Orientale basin, J. Geophys. Res., 110, doi :10.1029/2005JE002425.

627 Carr, M. H., 1990. D/H on Mars - Effects of floods, volcanism, impacts, and polar 628 processes, Icarus (ISSN 0019-1035), vol. 87, Sept. 1990, p. 210-227.

629 Carter, L. M., et al., 2009. Dielectric properties of lava flows west of Ascraeus Mons. 630 Geophysical Research Letters. 36, doi:10.1029/2009GL041234. 
631 Clifford, S. M., 1993. A model for the hydrologic and climatic behavior of water on

632 Mars. J. Geoph. Res., 98, 10973.

633 Clifford, S. M.; Parker, T. J., 2001. The Evolution of the Martian Hydrosphere:

634 Implications for the Fate of a Primordial Ocean and the Current State of the Northern 635 Plains, Icarus, Volume 154, Issue 1, pp. $40-79$.

636 Connerney, J. E. P., Acuña, M., Wasilewski, P. J., Kletetschka, G., Ness, N. F., 637 Rème, H., Lin, R. P., Mitchell, D. L., 2001. The Global Magnetic Field of Mars and 638 Implications for Crustal Evolution, Geoph. Res. Let., 28, 4015-4018, doi: $63910.1029 / 2001 G L 013619$.

640 Downs, G. S., Goldstein, R. M., Green, R. R., Morris G. A. and Reichley, P. E. 1973. 641 Martian topography and surface properties as seen by radar: The 1971 opposition. 642 Icarus, 18, 8-21.

643 Downs, G. S., Reichley, P. E. and Green, R. R. 1975. Radar measurements of Martian 644 topography and surface properties : The 1971 and 1973 oppositions. Icarus, 26, 273645312.

646 Duru, F., Gurnett, D., Averkamp, T., Kirchner, D., Huff, R., Persoon, A., Plaut, J., 647 Picardi, G., 2006. Magnetically controlled structures in the ionosphere of Mars $J$. 648 Geophys. Res., 111, 12204-+, doi: 10.1029/2006JA011975.

649 Espley, J., R., Farrell, W., Brain, V, Morgan, V, Cantor, B., Plaut, V, Acuña, M., 650 Picardi, G., 2007. Absorption of MARSIS radar signals: Solar energetic particles and 651 the daytime ionosphere, Geoph. Res. Let., 34, 9101-+, doi: 10.1029/2006GL028829.

652 Evans, J. V. 1962. Radio echoes studies of the Moon. In Physics and Astronomy of the 653 Moon, ed. Z. Kopal (Nea York : Academic Press), pp 429-479 
654 Evans, J. V. and Pettengill, G. H. 1963. The scattering behavior of the Moon at

655 wavelengths of 3.6, 68, and 784 centimeters. J. Geophys. Res. 68, 423-477.

656 Feldman, W. C., and 12 colleagues, 2002. Global Distribution of Neutrons from Mars:

657 Results from Mars Odyssey, Science, 297, 75-78

658 Feldman, W. C. and 14 colleagues, 2004. Global distribution of near-surface

659 hydrogen on Mars, J. Geophys. Res., 109, 9006-+, doi: 10.1029/2003JE002160.

660 Feldman, W. C., Prettyman, T. H., Maurice, S., Nelli, S., Elphic, R., Funsten, H. O.,

661 Gasnault, O., Lawrence, D. J., Murphy, J. R., Tokar, R. L., and Vaniman, D. T., 2005.

662 Topographic control of hydrogen deposits at low latitudes to midlatitudes of 663 Mars, J. Geophys. Res., 110, doi : 10.1029/2005JE002452.

664 Fialips, C. I., Carey, J. W., Vaniman, D. T., Bish, D. L., Feldman, W. C., and Mellon, M.

665 T., 2005. Hydration state of zeolites, clays, and hydrated salts under present-day

666 martian surface conditions: Can hydrous minerals account for Mars Odyssey

667 observations of near-equatorial water-equivalent hydrogen?, Icarus, 178, 74-83.

668 Fung, A. K., Li, Z., Chen, K. S., 1992. Backscattering from a randomly rough

669 dielectric surface, IEEE Transactions on Geoscience and Remote Sensing, 30, 356-

$670 \quad 369$

671 Grima, C., Kofman, W., Mouginot, J., Phillips, R., J., Hérique, A., Biccari, D., Seu, 672 R., Cutigni, M., 2009. North polar deposits of Mars: Extreme purity of the water ice, 673 Geoph. Res. Let., 36, 3203-+

674 Gurnett, D., and 10 colleagues, 2005. Radar Soundings of the Ionosphere of Mars 675 Science, 310, 1929-1933. 
676 Head, J. W., Mustard, J. F., Kreslavsky, M. A., Milliken, R. E., Marchant, D. R., 677 2003. Recent ice ages on Mars. Nature. 426, 797-802.

678 Heggy, E., Paillou, P., Costard, F., Mangold, N., Ruffie, G., Demontoux, F.,

679 Grandjean, G., Malézieux, J. M., 2003. Local geoelectrical models of the Martian 680 subsurface for shallow groundwater detection using sounding radars J. Geophys. Res., 681 108, 11-+, doi: 10.1029/2002JE001871.

682 Heggy, E., Clifford, S. M., Younsi, A., Miane, J. L., Carley, R., Morris, R. V., 2007. 683 On the Dielectric Properties of Dust and Ice-Dust Mixtures: Experimental 684 Characterization of the Martian Polar-layered Deposits Analog Materials. Lunar and 685 Planetary Institute Conference Abstracts, Vol. 38, 2007, pp. 1756.

686 Jakosky, B. M., Mellon, M. T., Varnes, E. S., Feldman, W. C., Boynton, W. V., 687 Haberle, R. M., 2005. Mars low-latitude neutron distribution: Possible remnant near688 surface water ice and a mechanism for its recent emplacement, Icarus, 175, 58-67.

689

690 Kreslavsky, M., A., Head, J. W., 2000. Kilometer-scale roughness of Mars: Results 691 from MOLA data analysis, J. Geophys. Res., 105, 26695-26712, 692 doi:10.1029/2000JE001259.

693 Krupenio, N. N., 1977. Map-plot of the dielectric constant and density of Martian 694 surface soil, Kosmicheskie Issledovaniia, 15, 470-474.

695 Leblanc, F., and 14 colleagues, 2008. Observations of aurorae by SPICAM ultraviolet 696 spectrograph on board Mars Express: Simultaneous ASPERA-3 and MARSIS 697 measurements, J. Geophys. Res., 113, 8311-+, doi: 10.1029/2008JA013033.

698 Mangold, N., 2005. High latitude patterned grounds on Mars: Classification, 
699

700

701

702

703

704

705

706

707

708

709

710

711

712

713

714

715

716

717

718

719

720

distribution and climatic control. Icarus. 174, 336-359.

Maxwell Garnett, J. C., 1904. Colours in metal glasses and metal films. Transaction of the Royal Society of London CCIII, 481-502.

Mellon, M., Jakosky, B. M., 1993. Geographic variations in the thermal and diffusive stability of ground ice on Mars. Journal of Geophysical Research. 98, 3345-3364.

Mellon, M. T., Feldman, W. C., Prettyman, T. H., 2004. The presence and stability of ground ice in the southern hemisphere of Mars. Icarus. 169, 324-340.

Mellon, M. T., Arvidson, R. E., Marlow, J. J., Phillips, R. J., Asphaug, E., 2008. Periglacial landforms at the Phoenix landing site and the northern plains of Mars. Journal of Geophysical Research-Planets. 113.

Mitrofanov, I., and 11 colleagues, 2002. Maps of Subsurface Hydrogen from the High Energy Neutron Detector, Mars Odyssey, Science, 297, 78-81.

Mouginot, J., Kofman, W., Safaeinili, A., Herique, A., 2008. Correction of the ionospheric distortion on the MARSIS surface sounding echoes, Plan. and Space Sci., $56,917-926$

Mouginot, J., Kofman, W., Safaeinili, A., Grima, C., Herique, A., Plaut, J. J. 2009.

MARSIS surface reflectivity of the south residual cap of Mars, Icarus 201, 454-459

Niles, P. B., Michalski, J., 2009. Meridiani Planum sediments on Mars formed through weathering in massive ice deposits. Nature Geoscience. 2, 215-220.

Neumann, G. A.; Abshire, J. B.; Aharonson, O.; Garvin, J. B.; Sun, X.; Zuber, M. T., 2003. Mars Orbiter Laser Altimeter pulse width measurements and footprint-scale roughness, Geophysical Research Letters, Volume 30, Issue 11, pp. 15-1. 
721 Nouvel, J. F., 2002. Sondage du sous-sol martien par un radar basse-fréquence depuis

722 un satellite en orbite basse: analyses physiques et préparation des données, $\mathrm{PhD}$

723 Thesis, Université Joseph Fourier, Grenoble.

724 Nouvel, J., F., Herique, A., Kofman, W., Safaeinili, A., 2004. Radar signal 725 simulation: Surface modeling with the Facet Method, Radio Sci., 39, RS1013

726 Petrenko, V. F., Whitworth, R. W., 1999. Physics of Ice. Oxford Univ. Press, New 727 York.

728 Pettengill, G. H., Shapiro, I. I., and Rogers, A. E. E. 1973. Topography and radar 729 scattering properties of Mars. Icarus, 18, 22-28.

730 Picardi, G., and 12 colleagues, 2004. Performance and surface scattering models for 731 the Mars Advanced Radar for Subsurface and Ionosphere Sounding (MARSIS). 732 Planetary and Space Science. 52, 149-156.

733 Picardi, G., and 33 colleagues, 2005. Radar Soundings of the Subsurface of Mars, 734 Science, 310, 1925-1928.

735 Plaut, J., J., and 23 colleagues, 2007. Subsurface Radar Sounding of the South Polar 736 Layered Deposits of Mars, Science, 316, 92-95.

737 Safaeinili, A., Kofman, W., Nouvel, J. F., Herique, A., Jordan, R., 2003. 738 Impact of Mars ionosphere on orbital radar sounder operation and data processing, 739 Plan. and Space Sci., 51, 505-515.

740 Safaeinili, A., Kofman, W., Mouginot, J., Gim, V, Herique, A., Ivanov, A., Plaut, J., 741 Picardi, G., 2007. Estimation of the total electron content of the Martian ionosphere 742 using radar sounder surface echoes, Geoph. Res. Let., 34, 23204-+, 
doi:10.1029/2007GL032154.

744 Schorghofer, N., Aharonson, O., 2005. Stability and exchange of subsurface ice on

745 Mars. Journal of Geophysical Research-Planets. 110, 16.

746 Seu, R., and 11 colleagues, 2007. SHARAD sounding radar on the Mars

747 Reconnaissance Orbiter, J. Geophys. Res., 112, doi :10.1029/2006JE002745.

748 Sihvola, A., 1999. Electromagnetic mixing formulas and applications. IEEE.

749 Simpson, R. A., Tyler, G. L., Brenkle, J. P. and Sue, M. 1979. Viking bistatic radar 750 observations of the Hellas Basin on Mars: Preliminary results, Science, 203, 153-173.

751 Simpson, R. A., Tyler, G. L. Harmon, J. K. and Peterfreund, A. R. 1982. Radar 752 measurement of small-scale surface texture : Syrtis Major, Icarus, 49, 258-283.

753 Simpson, R. A, Harmon, J. K, Zisk, S. H, Thompson, T. W. and Muhleman, D. O.

754 1992. Radar determination of Mars surface properties in Mars, The university of 755 Arizona Press, p. 652-685.

756 Smith, D. E., and 23 colleagues, 2001. Mars Orbiter Laser Altimeter: Experiment 757 summary after the first year of global mapping of Mars, J. Geophys. Res., 106, 23689758 23722, doi:10,1029/2000JE001364.

759 Smith, M. D., 2004. Interannual variability in TES atmospheric observations of Mars 760 during 1999-2003. Icarus. 167, 148-165.

761 Smith, P. H., and 35 colleagues, 2009. $\mathrm{H}_{2} \mathrm{O}$ at the Phoenix landing site. Science, 325, 762 58-61.

763 Squyres, S. W., Clifford, S. M., Kuzmin, R. O., Zimbelman, J. R., Costard, F. M., 764 1992. Ice in the Martian Regolith. In: H. H. Kieffer, (Ed.), Mars. The University of 
765 Arizona Press.

766 Squyres, S. W., and 18 colleagues, 2004. In Situ Evidence for an Ancient Aqueous 767 Environment at Meridiani Planum, Mars. Science. 306, 1709-1714.

768 Ulaby, F., Moore, T. R., Fung, A., 1986. Microwave Remote Sensing, Artech House 769 Publishers.

770 Washburn, A. L., 1980. Permafrost features as evidence of climatic change, Earth 771 Science Reviews, Volume 15, Issue 4, p. 327-402.

772 Watters, T. R., and 12 colleagues, 2007. Radar Sounding of the Medusae Fossae 773 Formation Mars: Equatorial Ice or Dry, Low-Density Deposits?, Science, 2007, 318, 7741025.

775 Williams P. J., Smith M. W., 1989. The Frozen Earth: Fundamentals of Geocryology,

776 Cambridge University Press, , Cambridge (1989). ISBN 05213653341.

778

779

780

781 


\section{Figure Captions}

785 Figure 1: Top: a typical MARSIS pulse measured over the South Polar Layered 786 Deposits (orbit \#2682, pulse 718) in $\mathrm{dB}$. The surface echo is recorded at about $\mathrm{t}=130$ $787 \mu$ s after the opening of the receiver's window. Another strong echo, attributed to the 788 reflection on the bedrock below this ice, is received at $\mathrm{t}=170 \mu \mathrm{s}$. Bottom: the criteria $789 \mathrm{C}$ as defined in equation 1 calculated for the same MARSIS pulse. The position of the 790 surface echo is indisputably highlighted by the high value of $C$,

791 Figure 2. Top to bottom: the radargram of orbit \#2787, the position of the surface 792 echo detected by our algorithm, the power reflected by the surface in $\mathrm{dB}$.

793 Figure 3 (a) Left: raw reflectivity as function of the Solar Zenith Angle (SZA). (b) 794 Right: mean reflectivity as function of the Total Electron Content. Both graphics have 795 been plotted using the entire set of data at $4 \mathrm{MHz}$.

796 Figure 4. Reflectivity corrected for absorption as function of the total electron 797 content. The graph has been plotted using the entire set of data at $4 \mathrm{MHz}$.

798 Figure 5. A: Reflectivity map at 3-5 $\mathrm{MHz}$ of the Martian surface as seen by 799 MARSIS. Red corresponds to high reflectivity and blue to low reflectivity. Grey 800 regions correspond to a lack of data. The map is in cylindrical projection. The spatial 801 resolution is 0.5 bin per degree.

802 B: Reflectivity map based on simulated radargrams. Grey regions correspond to a 803 lack of data. The map is a cylindrical projection. The resolution is 0.5 bin per degree. 
805 Figure 6. The image on the left has been provided by HIRISE on board MRO 806 (PSP_001736_2605, credit: NASA/JPL/University of Arizona). This image with 25 $807 \mathrm{~cm}$ resolution per pixel shows in detail the dunes in Olympia Undae. The radargram 808 on top corresponds to a part of orbit \#3674 of MARSIS/MEX over this region. The 809 bottom image is the MOLA topography corresponding to the MARSIS track.

810 Figure 7. Reflectivity map corrected for roughness effect. As described in the text, 811 the reflectivity has been calibrated using a reference making it possible to provide the 812 corresponding dielectric constant. The map is a cylindrical projection. The spatial 813 resolution is one bin per degree. Grey background corresponds either to a lack of data 814 or a removal of data corrupted by artefacts (effects of magnetic field, high surface 815 roughness).

816 Figure 8: (A) MARSIS dielectric map. Same as figure 7.

(B) Global interpolation of the dielectric map (A) using 8-order spherical harmonics adjustment. (C) Global map of hydrogen concentration in the top meter of the regolith obtained by the neutrons spectrometer of the GRS / Mars Odyssey instruments suite (data from Feldman et al., 2004). Concentration is expressed as Water Equivalent Hydrogen abundance in weight percent.

24 All maps are gridded in Robinson projection.

825 Figure 9: Longitudinal averages of MARSIS surface real dielectric constant and GRS 826 neutrons spectrometer WEH concentration. Red crosses correspond to the dielectric 
828 curve corresponds to the interpolated MARSIS map (figure 8.B). WEH values are

829 calculated from the map plotted in figure 8.C.

830 Figure 10: A: Visible color map (Viking), B: Thermal inertia map (TES), C:

831 MARSIS reflectivity map. The comparison between these maps shows that the limits

832 displayed on the MARSIS reflectivity map do not correspond to systematic changes

833 of albedo and thermal inertia, indicating that the surface material remains unchanged

834 while subsurface material is different. 
835 Tables

$\begin{array}{cccc}\text { Central Frequency } & \mathbf{3} \mathbf{~ M H z} & \mathbf{4 ~ M H z} & \mathbf{5 ~} \mathbf{M H z} \\ \text { Total electron Content }\left(\mathbf{1 0}^{\mathbf{1 5}} \mathbf{m}^{-\mathbf{2}}\right) & 3 & 7.5 & 7.5 \\ \text { Solar Zenith Angle } & 85^{\circ} & 70^{\circ} & 60^{\circ}\end{array}$

836

837 Table 1. Summary of the limits used to select the data. Measurements are kept when

838 the total electron content is below the limit indicated by the first line and when the

839 solar zenith angles are above the limit indicated by the second line.

840 

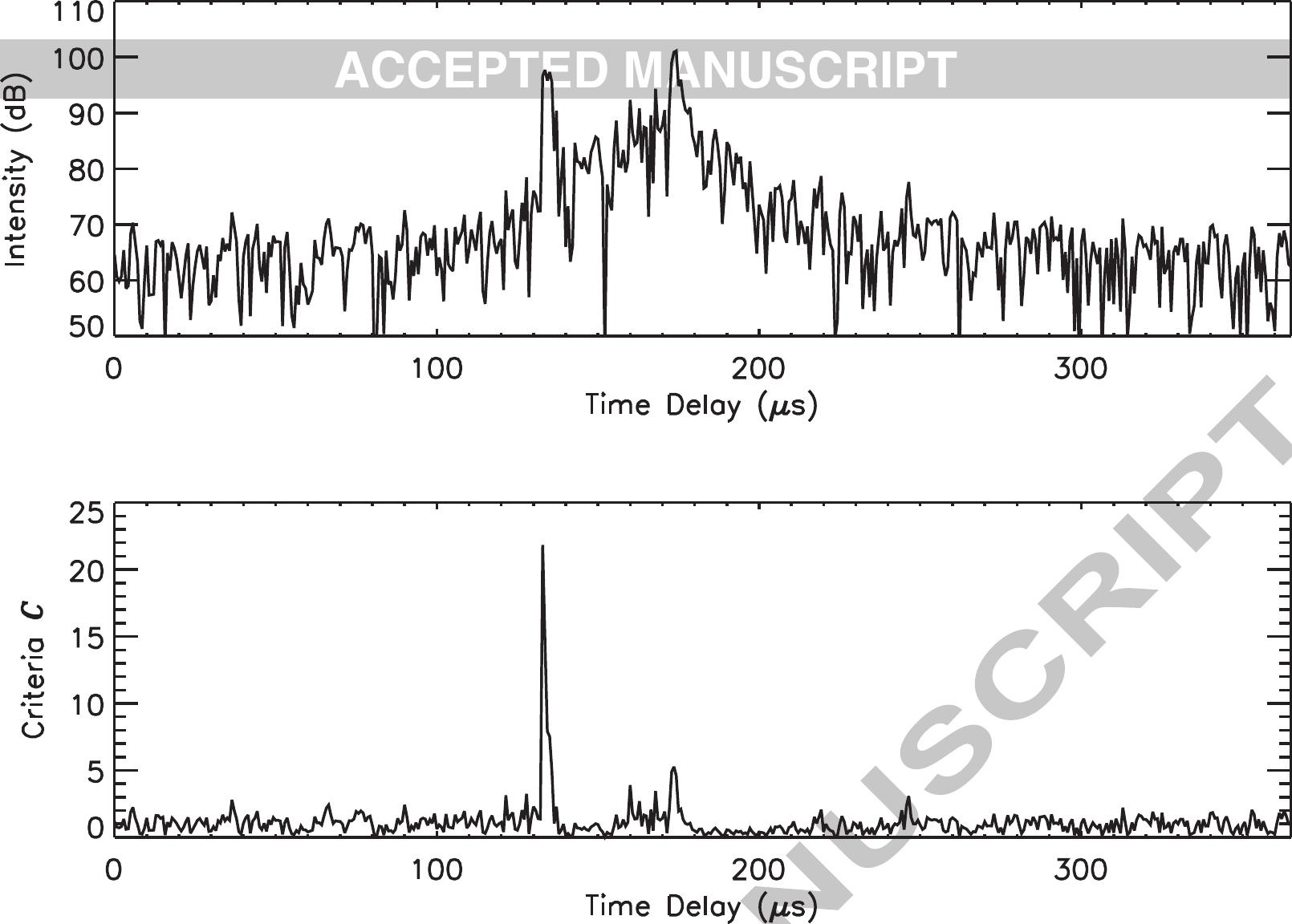


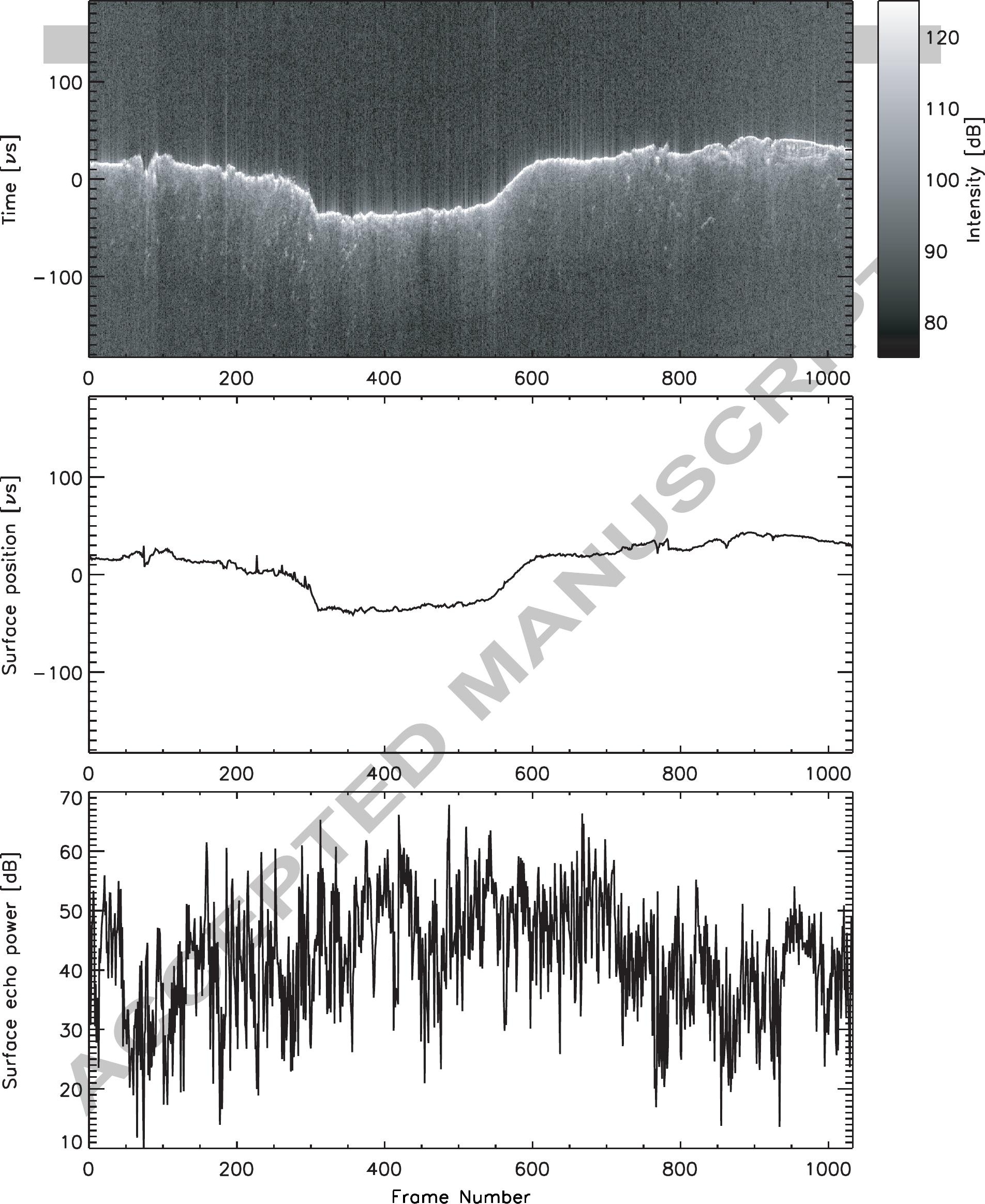


ACCEPTED MANUSCRIPT

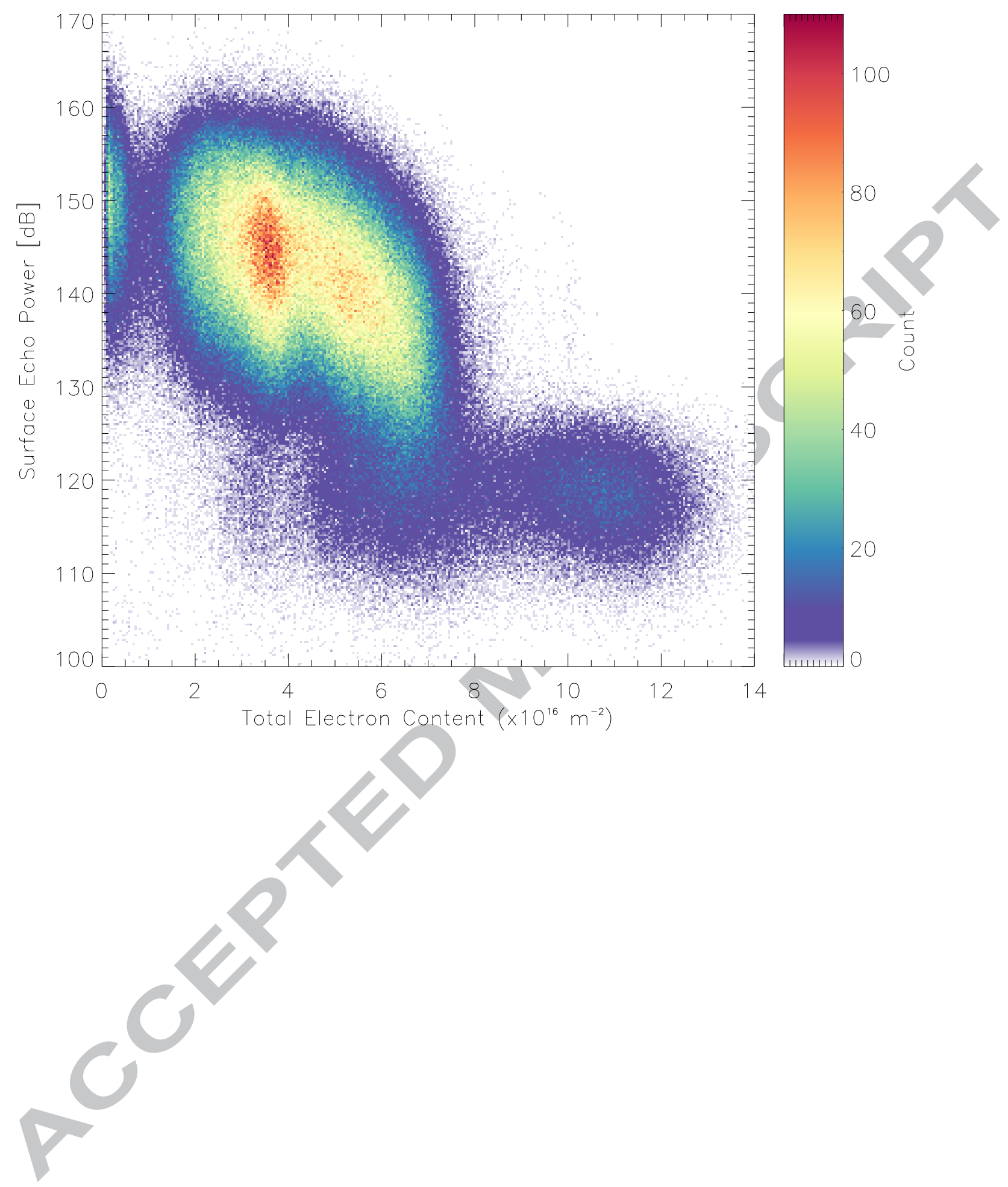


ACCEPTED MANUSCRIPT

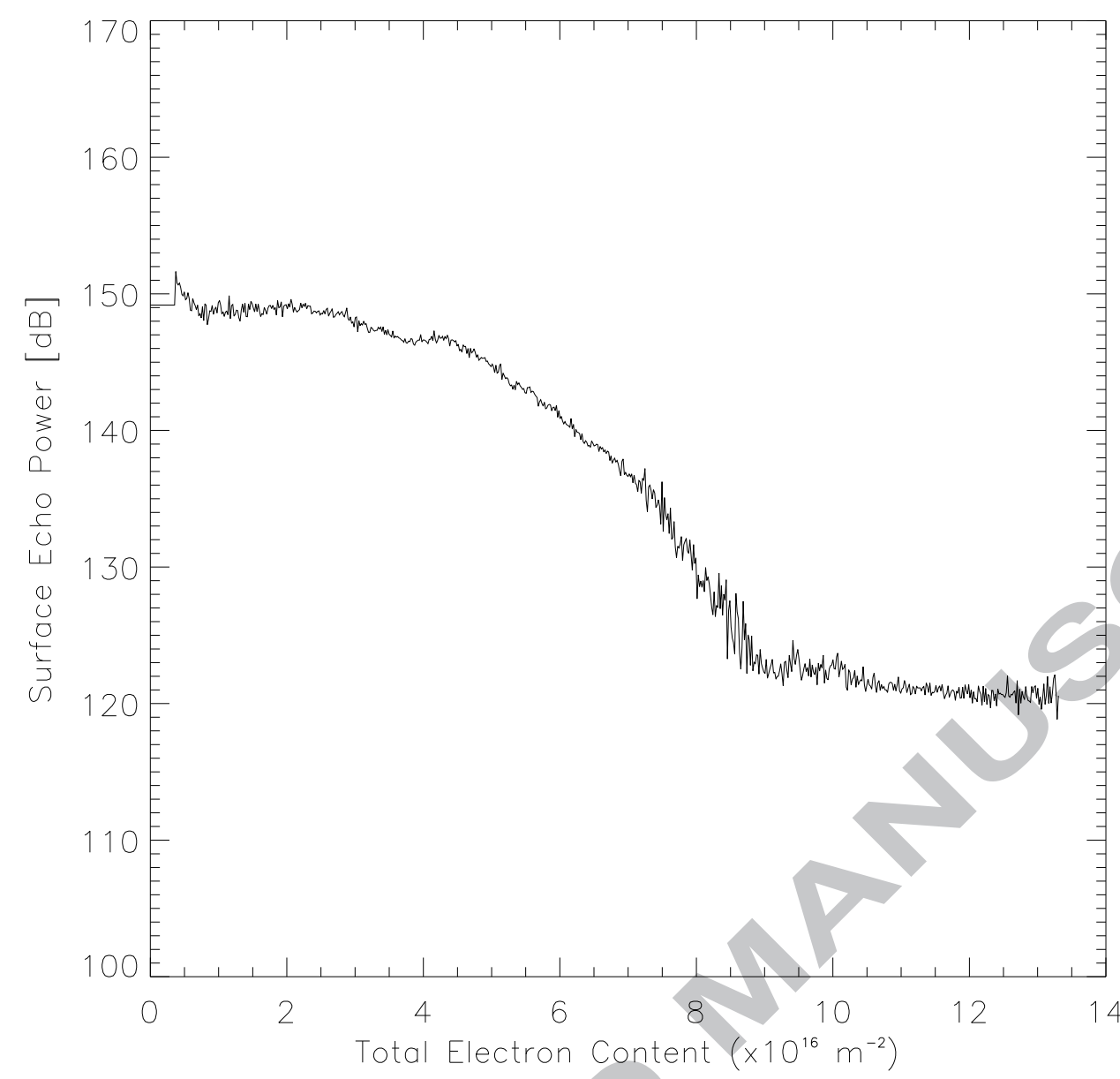


ACCEPTED MANUSCRIPT

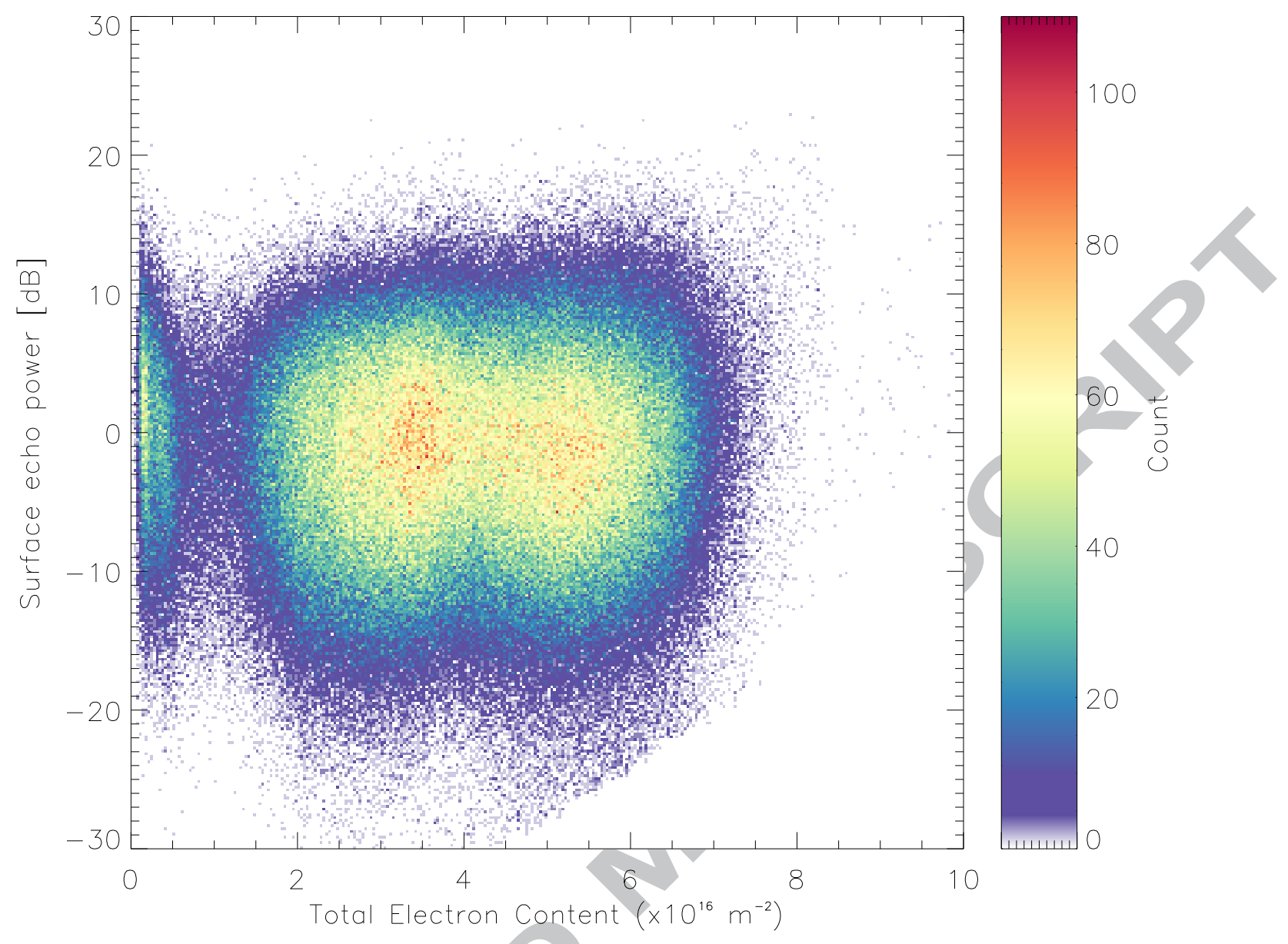




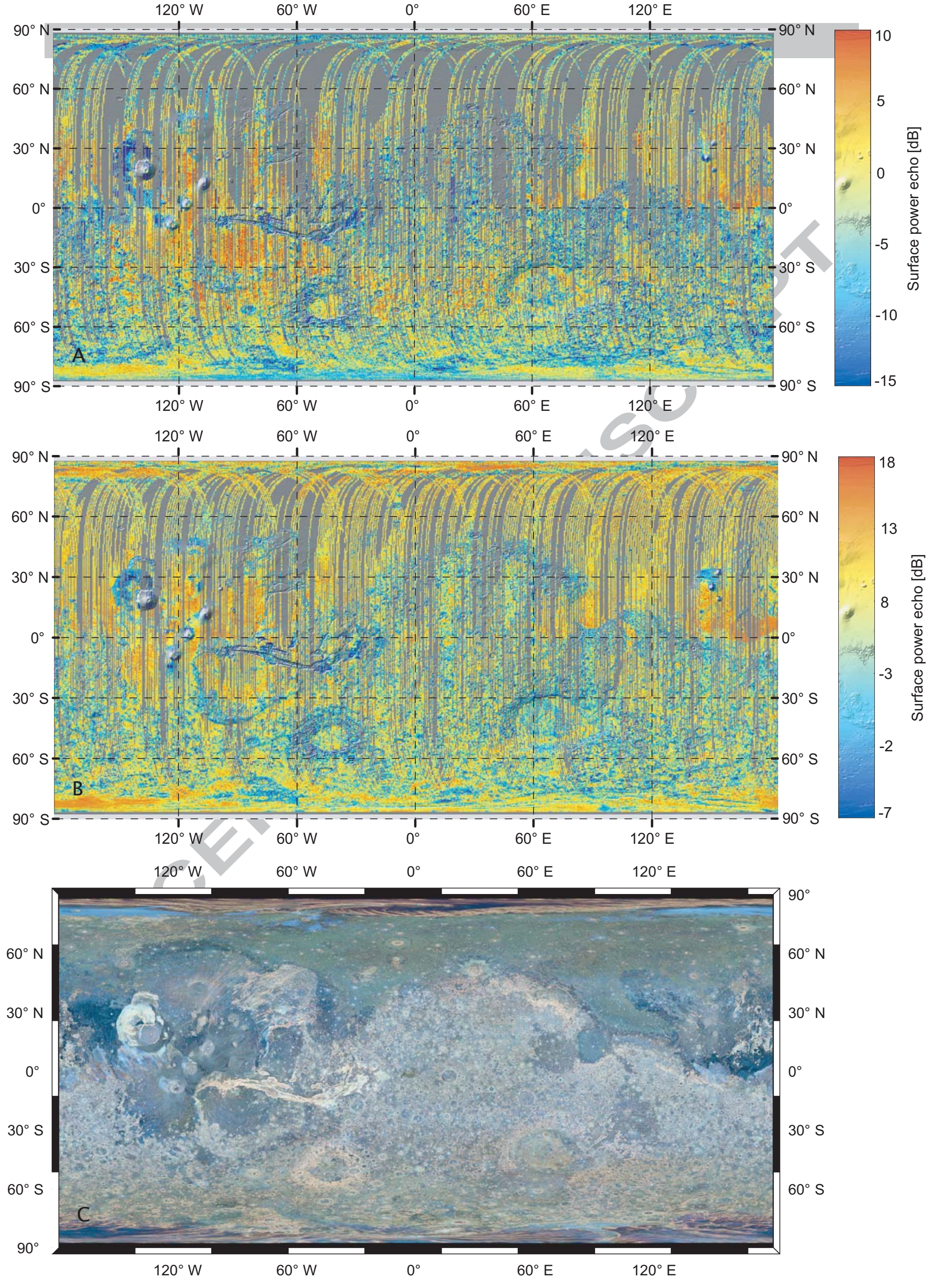


3674

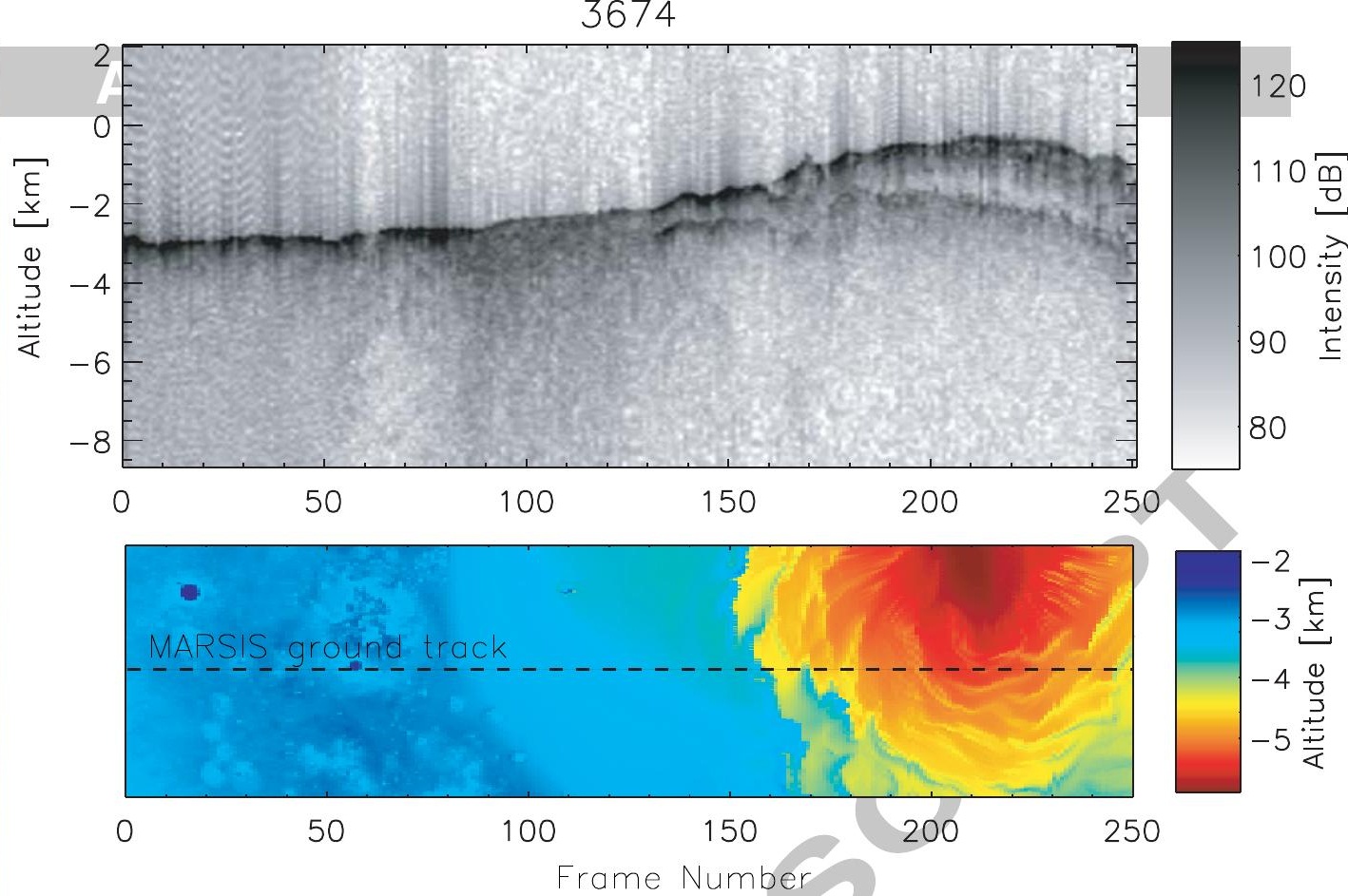




\section{ACCEPTED MANUSCRIPT}

Real Dielectric Constant

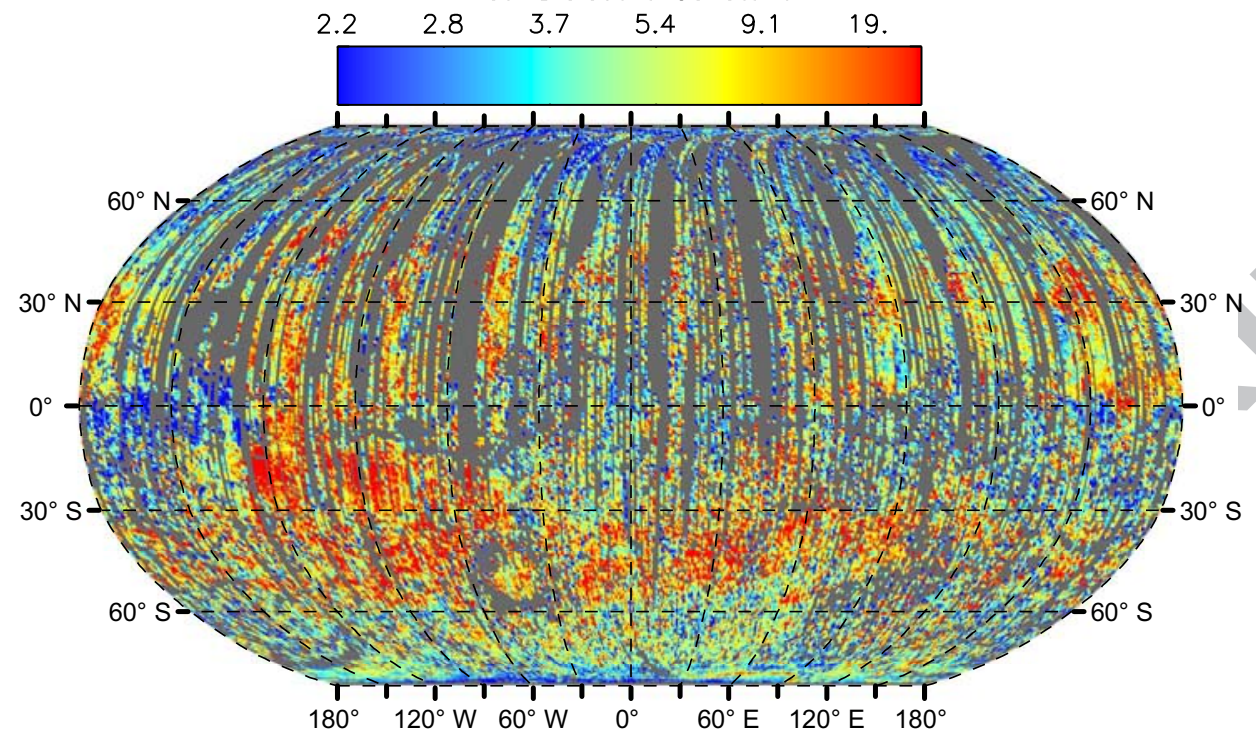




\section{ACCEPTED MANUSCRIPT}
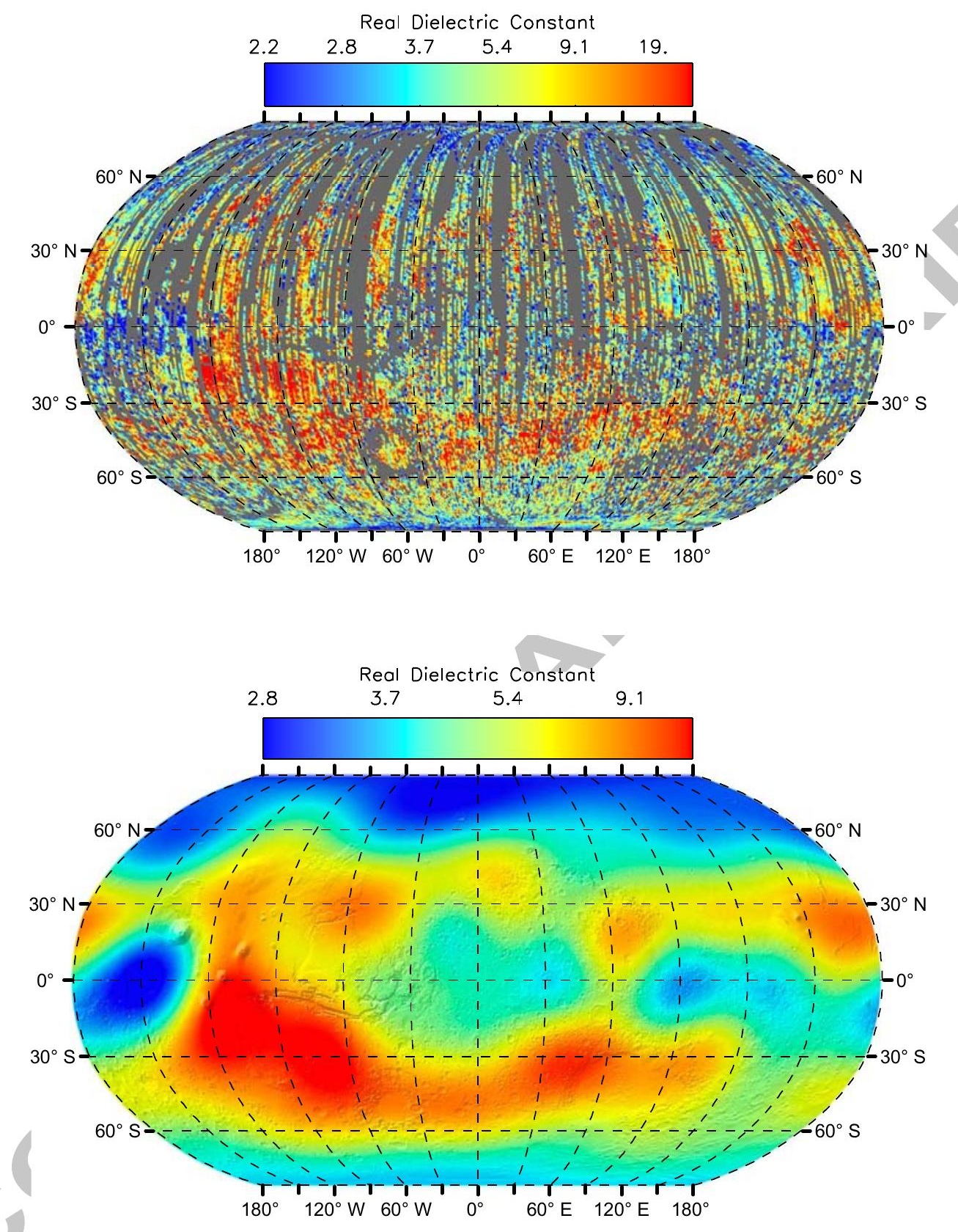

Water Equivalent Hydrogen Abundance

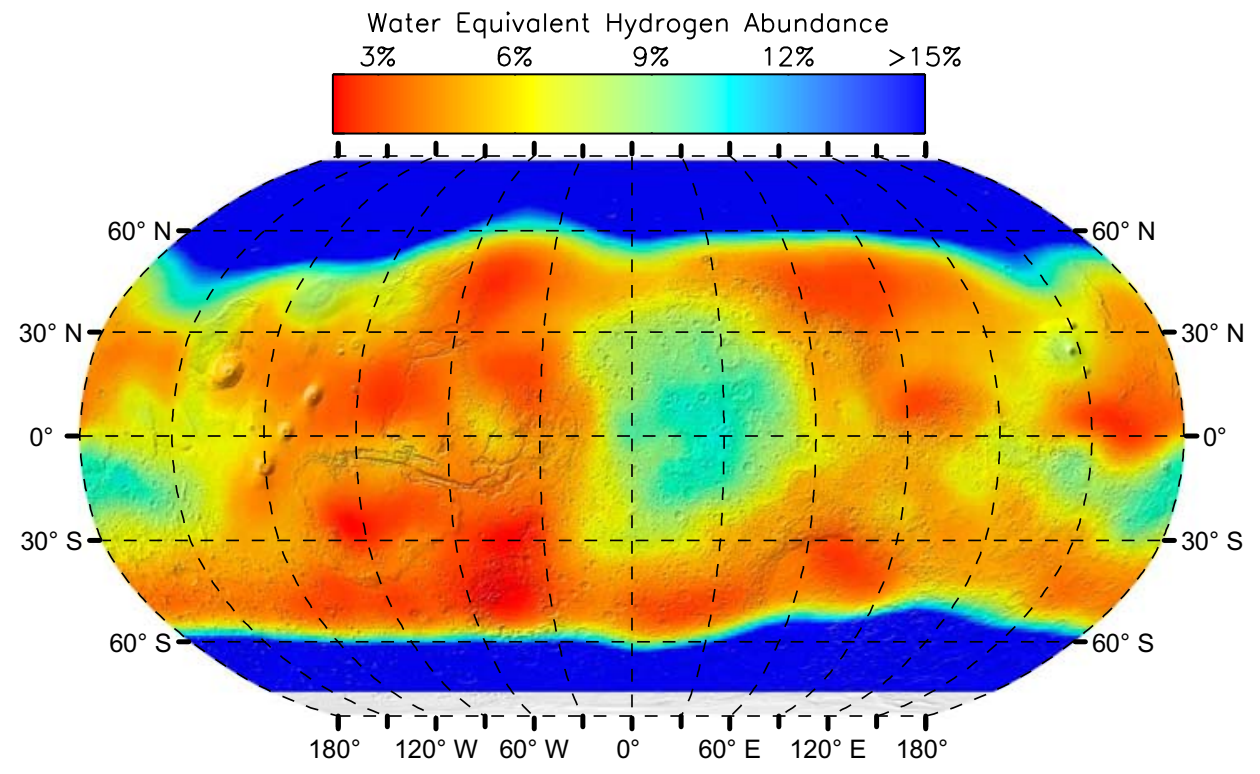



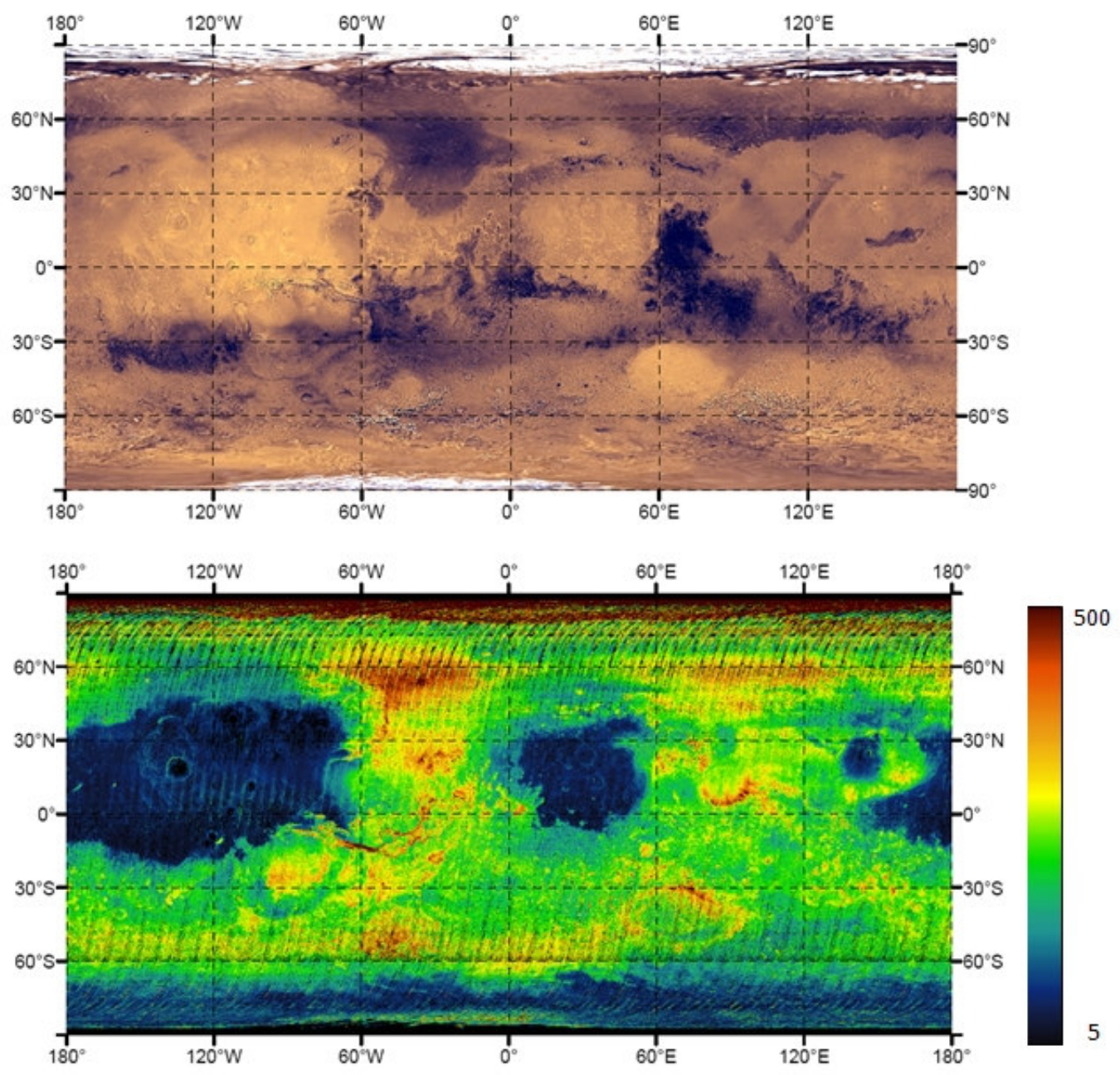

हैं

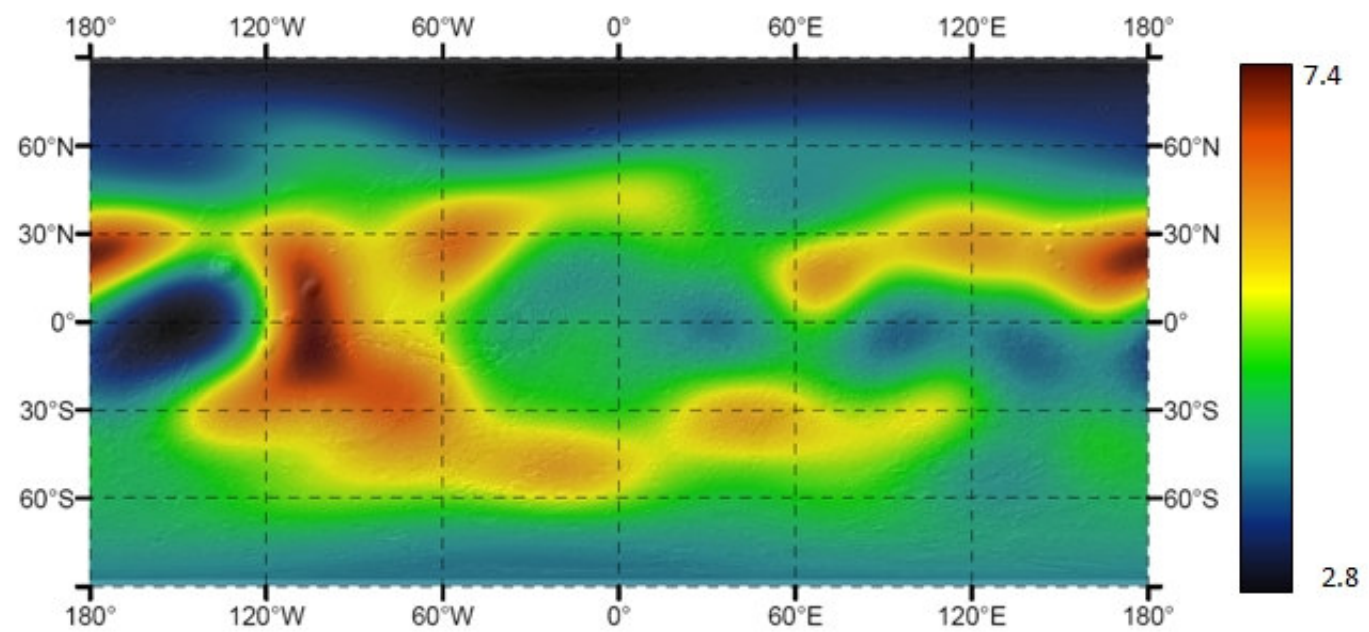


Elsevier Editorial System(tm) for Icarus

Manuscript Draft

Manuscript Number: ICARUS-11322R3

Title: The 3-5 MHz global reflectivity map of Mars by MARSIS/Mars Express: implications for the current inventory of subsurface H2O.

Article Type: Regular Article

Keywords: Mars, surface

Radar observations

Data reduction techniques

Corresponding Author: Dr. Jeremie Mouginot, Ph.D.

Corresponding Author's Institution: University of California

First Author: Jeremie Mouginot, Doctor

Order of Authors: Jeremie Mouginot, Doctor; Antoine Pommerol; Wlodek Kofman; Pierre Beck; Bernard Schmitt; Cyril Grima; Alain Herique; Ali Safaeinili; Jeffrey J Plaut

Abstract: We extracted the surface echo power from two years of MARSIS measurements. The retrieved values are calibrated to compensate for changes in the distance of the spacecraft to the surface and for the attenuation of the signal by the ionosphere. The results are used to build the first global map of surface echo power at 3-5 MHz. The surface echo power variations are primarily caused by $\mathrm{km}$-scale surface roughness. Then, we derive the values of dielectric constant of the shallow subsurface materials by normalizing the surface echo power map using a simulation of MARSIS signal from the MOLA topography. As a result, we obtain a map that characterizes the dielectric properties of the materials down to a few decameters below the surface. Dielectric properties vary with latitude, with high values in mid-latitudes belts $\left(20-40^{\circ}\right)$ and lower values at both equatorial and high latitudes. From the comparison of MARSIS reflectivity map to GRS observations, we conclude that the reflectivity decrease observed poleward of $50-60^{\circ}$ corresponds to the onset of water-ice occurrence within the regolith. Assuming homogenous ground composition and texture at the scale of the MARSIS resolution cell, our inferred volume of ground water ice is of $106 \mathrm{~km} 3$, equivalent to a polar cap. Low reflectivity areas are also observed in equatorial regions. From radar studies alone, equatorial low dielectric constant values could have different interpretations but the correlation with GRS hydrogen distribution rather points toward a water related explanation. 